\title{
PEQUEÑA EXPLOTACIÓN, CAMBIO PRODUCTIVO Y CAPITAL BRITÁNICO EN EL ALTO VALLE DEL RÍO NEGRO (1900-1948)(*)
}

\author{
Susana Bandieri \\ Graciela Blanco ${ }^{(0)}$
}

\section{Introducción}

Entendido como región, el Alto Valle del río Negro comprende asimismo los valles inferiores de sus tributarios los ríos Limay y Neuquén, extendiéndose por encima de los límites políticos entre las provincias de Río Negro y Neuquén y conformando una zona de especiales características en el Norte de la Patagonia argentina. Esta área productiva comprende en la actualidad unas 100.000 ha bajo riego con una producción de 700.000 tn de peras y manzanas destinadas mayoritariamente a la exportación.

Si bien la fertilidad de la zona y sus posibilidades productivas fueron percibidas desde el momento mismo de la conquista militar del territorio a los grupos indígenas en el año 1879, su puesta en producción efectiva a partir de la construcción de grandes obras de riego se inició hacia comienzos del siglo actual y se estructuró definitivamente como eco-

(-) Este trabajo es parte de la investigación histórica realizada por las autoras para el PID/CONICET: "El minifundio en el Alto Valle del Río Negro: estrategias de adaptación", dirigido por el Lic. Gerardo de Jong.

(•) Licenciadas en Historia, investigadoras del CEHIR y CONICET, respectivamente [Centro de Estudios de Historia Regional, Dpto. de Historia, Fac. de Humanidades, Universidad Nacional del Comahue. Av. Argentina 1400 (8300), Neuquén. Tel. 099-490388-E-mail: sbandier@uncoma.edu.ar]. 
nomia frutícola alrededor del año 1930, cuando la producción regional se orientó definitivamente hacia el mercado externo. Previo a ello, la incorporación progresiva de superficies regables produciría un consecuente proceso de subdivisión y venta de las grandes propiedades territoriales originadas en la conquista militar, que se acentuó a lo largo de la década de 1920 contribuyendo a la constitución, como agente económico mayoritario, de un pequeño productor propietario relativamente próspero que fuera durante muchos años el sujeto social característico del desarrollo económico del Valle.

Sobre fines de la década de 1970 se observa el inicio de una crisis generalizada de la producción frutícola regional, vinculada tanto a los mercados de exportación como a cuestiones de política económica interna, que afectó particularmente al mencionado agente económico mayoritario provocándole falta de rentabilidad, notable atraso tecnológico y un acentuado proceso de descapitalización. Sin embargo, se evidencia la existencia de algunas empresas del sector concentrado de capital, relacionadas a la industria del frío, empaque y comercialización, que han intentado mantener el nivel de ganancia que tuvieron en la época de su mayor competitividad a escala mundial-lo que oportunamente contribuyó a la fuerte capitalización del sector-, a expensas de otras empresas en los rubros de producción primaria y ciertos sectores de empaque. Corroborando lo dicho, un estudio del año 1986 ya probaba que a esa fecha sólo tenían tasa de ganancia positiva las explotaciones por encima de 15 ha con rendimientos anuales superiores a $45.000 \mathrm{~kg} / \mathrm{ha}$ de fruta (de Jong et al., 1986). Teniendo en cuenta que según el Censo Frutícola del año 1974 existía entonces una alta incidencia de los predios de menos de 10 ha $(63 \%)$ sobre el total de los establecimientos, y que estos productores -según el último estudio mencionado- se encontrarían en franco proceso de descapitalización, podemos inferir el caracter minifundista que en los últimos años han adquirido los mismos. Las explotaciones menores de 5 ha, por su parte, ya habrían pasado casi totalmente al nivel de subsistencia.

Un primer abordaje de la temática implicó el estudio de esos productores minifundistas y las estrategias de adaptación seguidas para su permanencia dentro de la actividad, lo cual llevó a analizar la problematica del desarrollo regional mediante un marco conceptual que considerase los mecanismos de generación y acumulación de excedentes característicos de la misma. Se partió entonces de considerar que alrededor de una actividad vertebradora -en este caso la fruticultura- se vinculan un conjunto de empresas localizadas en la región o fuera de ella entre las cuales se desarrollan relaciones directas de acumulación que encierran, en sí mismas, una gran desigualdad y definen en conjunto un sólo ám- 
bito de acumulación que se denomina "subsistema" (Levín, 1974). Normalmente, la condición de existencia de altas tasas de ganancia en las empresas que pertenecen a la porción concentrada del capital desembolsado en la actividad son las bajas tasas de ganancia de la porción fragmentada del mismo. Es así como las primeras tienen una incidencia destacada en los mecanismos de formación del precio. De este modo, un chacarero recibe por su producto el precio que fijan las empresas de transformación e intermediación -que se aseguran una ganancia superior a la media- en las etapas avanzadas del subsistema hasta la elaboración del producto final. La consecuencia es que estos sectores productores, para permanecer dentro del subsistema -y por lo tanto de la actividad- en épocas de crisis, deben recurrir a la disminución de sus costos entrando normalmente en serios procesos de descapitalización que provocan, consecuentemente, el deterioro en el manejo de los recursos, el atraso tecnológico y deficiencias en la calidad del producto, todo lo cual redunda en su transformación en minifundistas y, progresivamente, en el deterioro del conjunto del subsistema (de Jong et alt. y de Jong, 1993; 1995).

La comprensión del funcionamiento de este último está estrechamente ligada, entonces, a la identificación de las empresas o actores sociales que en él intervienen, al conocimiento de las formas en que tiene lugar la generación de excedentes y a las modalidades del proceso de acumulación respectivo. De alli la necesidad de intentar reconstruir las características históricas de tales procesos en sus aspectos cualitativos y, de ser posible, también cuantitativos, para apreciar los cambios y/o supervivencias en el uso de los recursos, en las modalidades tecnológicas y en el surgimiento y/o desaparición de distintos agentes económicos. En suma, intentar reconstruir el funcionamiento histórico del subsistema frutícola regional.

Este estudio constituyó el primer paso en el intento de aproximarnos a la identificación del actor social más representativo de la fruticultura regional -en términos de unidades de explotación pequeñas consideradas óptimas en las primeras etapas de la actividad-, su vinculación con otros agentes económicos y sus posibilidades de acumulación del valor generado. Esta aproximación de base era de sustancial importancia para poder avanzar en la explicación de la situación que habría llevado, en los últimos años, a este pequeño productor próspero, a convertirse en minifundista con grandes dificultades para mantenerse dentro de la actividad.

Partimos de la hipótesis que, hacia 1930, la direccionalidad productiva de la región 
estuvo fuertemente orientada por una empresa de capitales británicos, estrechamente vinculada al ferrocarril, que controló la comercialización de la fruta fresca que por ese medio se transportaba a Buenos Aires para ser destinada prioritariamente al mercado externo. Sin intervenir directamente en la producción y renunciando a la integración vertical, esta empresa habría logrado monopolizar el transporte y comercialización de la fruta del Valle, incidiendo fuertemente en la fijación de los precios. La expansión de los cultivos en el área, donde según se verá dominaban las explotaciones menores de 10 ha, ya permitía suponer que éstas eran rentables sobre la base del monopolio productivo de la zona y la expansión de la demanda de los mercados externos. La aplicación del modelo formal de la metodología antes mencionada a un ejemplo histórico, nos permitió probarlo.

Esta etapa, que en principio extendimos hasta el año 1948 en coincidencia con la nacionalización de los ferrocarriles y, consecuentemente, de la empresa de comercialización de la fruta -Argentine Fruit Distributors-, no necesariamente se cierra en esos años provocando la modificación de las características descriptas y el inicio definido de una nueva situación. Posteriores avances en la investigación permitieron comprobar que la desaparición de la firma inglesa, al atomizar el proceso de comercialización, provocó el surgimiento y expansión de otras empresas exportadoras y/o mayoristas independientes que paulatinamente incorporaron la tecnología necesaria para el tratamiento de la fruta post-cosecha (red de frío, sistemas complejos de embalaje y acondicionamiento, etc.), iniciando una progresiva integración vertical que les habría permitido posteriormente controlar los procesos de producción, empaque, frío y comercialización, obteniendo un producto de calidad capaz de competir en el mercado internacional. Las pequeñas explotaciones habrían quedado, por su parte, sujetas al mayor poder de negociación de estas firmas, produciendo fruta de inferior calidad con destino al consumo local y nacional y a las industrias de jugo, entrando en un sensible proceso de descapitalización que las induciría a bajar los costos (sistemas de sanidad deficientes, tecnología obsoleta, etc.) lo que redundaría en un manejo inadecuado del recurso y el consecuente deterioro del mismo.

Trataremos, a continuación, la etapa que comprende desde los inicios de la actividad sobre comienzos de siglo hasta 1948 en que se produjo la nacionalización de las empresas británicas. A los efectos de ubicar espacialmente a los actores sociales más relevantes, se verá el proceso de sudivisión de la tierra y la consecuente aparición del pequeño productor propietario, así como la evolución productiva de la región, para concluir con la caracterización cualitativa del funcionamiento del subsistema respectivo. 


\section{La subdivisión de la tierra}

El término "colonización" fue oficialmente utilizado con referencia al proceso de distribución de la tierra pública en el Alto Valle inmediatamente después de la ocupación militar del espacio en 1879. Pero ello no implicó necesariamente, y menos en los primeros años, un acceso directo del pequeño productor propietario a extensiones moderadas de tierra.

La distribución inicial de la tierra pública no presentó en el Alto Valle diferencias sustanciales con la producida en la generalidad de los Territorios Nacionales. El Estado debió cumplir el compromiso adquirido con los sectores que financiaron la campaña militar de 1879 (Ley del Empréstito $N^{\circ}$ 947/1878), a la vez que recompensar a los miembros del Ejército Nacional que la llevaron a cabo (Ley de Premios Militares $N^{\circ} 1628 / 1885$ ). Ambas formas de acceso, predominantes en el área, derivarian en importantes concentraciones de la propiedad, algunas veces en las mismas zonas reservadas teóricamente por el Estado para la "colonización". Tal es el caso, por ejemplo, de las tierras concedidads a reconocidas personalidades de los círculos oficiales porteños como los Generales Fernández Oro y Godoy, el Contralmirante Cordero y el ex-funcionario Marcos Zorrilla, entre otros. Este proceso de distribución adoptaría posteriormente distintas formas de subdivisión en directa relación con la implementación de obras de riego -particulares y oficiales-, la llegada del ferrocarril, la valorización de las tierras y el consecuente cambio productivo.

\section{Las primeras Colonias}

La primera colonia agrícola llamada General Roca fue creada en 1883 por disposición del Estado Nacional, siguiendo los lineamientos de la Ley $N^{\circ} 817 / 76$, asignándosele cerca de $\mathbf{4 2 . 0 0 0}$ ha de Valle entre las actuales comunas de Fernández Oro e Ing. Huergo, zona servida por el llamado "canal de los milicos" '. Con un simple criterio catastral, no productivo, fue dividida en 442 lotes de 100 ha llamados "chacras". Datos censales de 1888 indican que de 30.000 ha ya adjudicadas, alrededor del $80 \%$ pertenecían sólo a 4 de los 56 adjudicatarios. Asimismo, de la superficie bajo riego, más del $70 \%$ pertenecía a 9 adjudica-

1 Se llamó con ese nombre al primer canal de riego cuya construcción se iniciara en 1884 bajo la dirección del ingeniero sanjuanino Hilarión Furque recurriendo al trabajo de soldados, presidiarios, aborígenes y peones agricultores. Con una bocatoma sobre el río Neuquén, recorría $50 \mathrm{~km}$ atravesando la denominada Colonia Agrícola General Roca. 
tarios ${ }^{2}$. Es claro el proceso de concentración de la propiedad al que aludiéramos, pudiéndose mencionar los ejemplos de Hilarión Furque y la Sociedad Vitivinícola Sanjuanina y Manuel Marcos Zorrilla, entre otros. Sobre fines de siglo aún quedaban tierras fiscales de la colonia sin distribuir, en tanto que de los lotes concedidos un alto porcentaje estaban abandonados sin cumplirse las obligaciones impuestas por la ya citada Ley de Colonización. Asimismo, hacia mediados de la primera década del siglo, la extensión cultivada abarcaba menos del $4 \%$ de su superficie total ${ }^{3}$.

La baja producción y los concesionarios ausentes no hacen otra cosa que demostrar, por una parte, manifiestos fines especulativos de los adquirentes y, por la otra, las dificultades que los "colonos" civiles y militares efectivamente establecidos en el área debieron enfrentar, particularmente la falta de comunicaciones, las deficiencias del riego y las frecuentes inundaciones -en especial la producida en el año 1899-. La solución a estos problemas en el transcurso de las primeras décadas del siglo, bajo la activa participación del capital británico, definirían la posterior incorporación a la producción de las tierras del Valle, así como su valorización y consecuente proceso de subdivisión, para dar lugar al surgimiento del actor social que nos ocupa en tanto propietario de una pequeña parcela de tierra.

El problema del aislamiento quedó finalmente resuelto cuando la empresa británica del Ferrocarril del Sud prolongó el tendido de líneas férreas desde Bahía Blanca hasta la confluencia de los ríos Neuquén y Limay en 1899. Tal hecho, motivado originariamente en objetivos estratégicos del Poder Ejecutivo Nacional, tendría posteriormente para la zona -y para la empresa- importantes efectos económicos. En principio, generaría nuevas solicitudes de concesión de tierras públicas en el Valle por parte de influyentes particulares porteños con capital que promovieron la firma, a ese fin, del Decreto del 27 de setiembre de 1907 en el cual se les concedía expresa "preferencia" en el acceso a la adjudicación. Esta norma legal reducía el precio de las chacras de $\$ 50$ a $\$ 2,50$ la ha -valor mínimo establecido en la vigente ley de tierras $N^{\circ} 4167 / 1903-$, con la condición de que sus adquirentes conformaran cooperativas de irrigación aportando $\$ 50$ por ha en concepto de capital para la construcción de obras de riego. Dentro de los dos primeros años los solicitantes debían realizar una serie de mejoras en la chacra -desmonte, nivelación, cercado, construcción de vi-

2 Censo de Agricultura y Ganadería levantado en la Colonia Roca por Hilarión Furque en 1888. Cit. en Vapnarsky, C., 1983: 130.

3 Maida de Minolfi, E., 1980. 
vienda y sembrado parcial de la superficie-, depositando $\$ 10$ por ha como garantía del cumplimiento de tales obligaciones. Estas exigencias de capital inicial se justificaban expresamente en los considerandos del Decreto en virtud del alto costo que requería la puesta en producción de estas tierras, "...fuera del alcance de colonos agrícolas desprovistos de los recursos necesarios", motivo al cual se adjudicaba el fracaso de algunos intentos anteriores como el del primer contingente de inmigrantes alemanes en la Colonia General Roca ${ }^{4}$.

En función de lo establecido en el mencionado Decreto se creó la Cooperativa de Irrigación Colonia Roca -en áreas aledañas a las actuales comunas de Gral. Roca y Allen- y, en condiciones similares -Decreto 24/9/1910-, la Cooperativa Ltda. de Irrigación Colonia Cervantes (1911) y la Cooperativa del Este o "Cooperativa Francesa" (1912), ambas al Este de la primera, abarcando las actuales comunas de Cervantes, e Ing. Huergo y Mainqué respectivamente.

La formación de estas Cooperativas y la participación en las mismas de importantes capitalistas no significó necesariamente un mayor parcelamiento de la propiedad, como tampoco la efectiva puesta en producción de las tierras. Es así como, en el caso de la Cooperativa de Irrigación Colonia Roca se evidencia un importante acaparamiento de lotes por parte de grandes accionistas como los Piñeiro Sorondo, Hans Fluger, la Suc. Zorrilla y Manuel Cordiviola, entre otros ${ }^{5}$. La colonia, servida inicialmente por el viejo canal de los milicos -ahora mejorado por la cooperativa- tendría sin embargo un importante desarrollo productivo, evidente en el incremento del área cultivada de 1.200 ha a 17.000 ha en el transcurso de la década de $1910^{6}$. La superficie de las explotaciones incidiría, como luego veremos, en la perdurabilidad del cultivo extensivo de alfalfa. Sin embargo, a medida que se habilitó la red necional de riego, algunos propietarios como Marcelo Piñeiro Sorondo pusieron en marcha proyectos particulares de colonización. Así se conformó la Colonia "Los Viñedos" en parte del establecimiento del mismo nombre de los Piñeiro Sorondo, ubicada en el ámbito de la actual comuna de Allen. En este caso se fraccionaron 700 ha en 58 lotes de hasta 25 ha, a $\$ 1.300$ la ha promedio, adquiridos en remate mediante préstamos de colonización del Banco Hipotecario Nacional en diciembre de 1924. Según un informe del año

4 Ockier, M. C., 1987: 19-20.

5 Archivo Histórico Provincial, Libro de Informes N² 295, Vol. V, 1919/20.

6 Vapnarsky, C, 1983, 152. 
1928 esta Colonia había alcanzado un importante grado de prosperidad siendo los colonos antiguos vecinos de la región que disponían de algún capital y accedieron fácilmente al sistema crediticio?.

La Cooperativa Ltda. de Irrigación Colonia Cervantes, conformada por iniciativa del escritor español Vicente Blasco lbañez, que diera lugar a la colonia de igual nombre integrada por un grupo de inmigrantes valencianos, terminó en un completo fracaso por causas atribuibles a problemas técnicos derivados del sistema de riego por elevación mecánica y, especialmente, al abandono de que fueron objeto los colonos por parte del gestor de la iniciativa. Tras la dispersión de éstos, Blasco lbañez transfirió la concesión en bloque de las 2.500 ha otorgadas a la Cooperativa al ex-Ministro de Hacienda de la Nación Dr. José María Rosa, percibiendo por ello una considerable ganancia (compró a \$2,50 y vendió tres años después a $\$ 300$ la ha). Estas tierras permanecerían indivisas durante varios años más.

Finalmente, la Cooperativa del Este, también llamada "Francesa" por el origen de sus integrantes, fue otro ejemplo notorio de acaparamiento especulativo. Gestionada por el médico francés Santiago Doléris y un grupo de representados, obtuvo la adjudicación de alrededor de 6.000 ha. Fracasados los primeros intentos productivos por inconvenientes vinculados al costo del sistema de riego por elevación mecánica y a la inundación del año 1915, los lotes se concentraron en pocas manos y quedaron en gran parte incultos ${ }^{9}$. Doléris, quien llegó a reunir más de 1.000 ha en propiedad, las mantendría desocupadas por 14 años hasta después de la incorporación del área al sistema integral de riego en 1921, fecha en que decidió arrendar los distintos lotes ubicados en las proximidades de la Estación Ferri. Posteriormente, en 1927, los mismos fueron fraccionados y rematados, siendo adquiridos por antiguos vecinos de la zona que trabajaron como contratistas o medieros en otras propiedades para cubrir los gastos iniciales ${ }^{10}$.

7 Goti, A., 1928: 29.

8 Cfr. Maida, E., 1971.

9 Cfr. Ockier, M.,1988: 325 y sgtes.

10 Información más amplia sobre el particular en Goti, A., 1928. 
Desde el punto de vista productivo es evidente que en los casos mencionados se observan dos realidades distintas: el manifiesto desarrollo de la Cooperativa de Irrigación Colonia Roca, sostenido por empresarios capitalistas, y el mantenimiento improductivo de las restantes tierras "colonizadas" con carácter especulativo. Sin embargo, la concentración de la propiedad fue un elemento común a la casi totalidad de la superficie que abarcaba la Colonia Roca y recién se modificó durante la década de 1920 a medida que las distintas áreas quedaron integradas a la red nacional de irrigación.

La sóla excepción la constituyó la denominada Colonia Rusa, propiciada directamente por el Estado Nacional (Decreto 25/7/1906), que comenzó a constituirse en el año 1906. Se trató en este caso de colonos independientes de la colectividad judia de Rusia, que en un número aproximado de 20 familias accedieron a la propiedad de alrededor de 1.000 ha parceladas en fracciones de 50 ha, ubicadas en la parte Este de la Colonia Roca. El propósito inicial de radicar 200 familias de esa nacionalidad se vería finalmente frustrado por la acción oficial de retardar la efectiva entrega en posesión de los lotes y modificar las condiciones de poblamiento que exigían una mayor disponibilidad de capital según el Decreto del año 1907, ya mencionado. Sin embargo, a pesar de las durísimas condiciones de vida, las escasas familias asentadas lograron sus títulos de propiedad en los años 1910/11, poniendo sus chacras en producción mediante la utilización del sistema de riego de la Coop. Ltda. de Irrigación Colonia Roca hasta que en 1921 se habilitó la red fiscal de riego".

El proceso de subdivisión de la tierra tanto al Este como al Oeste de la Colonia Roca, se produciría en épocas distintas en directa relación con el desarrollo de obras de irrigación de origen particular y/o estatal. En el área de la Confluencia de los ríos Limay y Neuquén -Oeste de la Colonia Roca- las tierras originalmente en manos de grandes propietarios comenzaron a subdividirse a principios de siglo, valorizadas por la llegada del ferrocarril y el consiguiente corte del aislamiento. De éstas, aquellas ubicadas en la margen izquierda del río Neuquén, en el valle inferior del mismo -entre la actual comuna de Contralmirante Cordero y la Confluencia-, habían sido inicialmente concedidas en el año 1883 a la Soc. Vitivinícola Sanjuanina, integrada por el Ing. Hilarión Furque y los hermanos Ventura y Alejandro Capella, entre otros -todos ellos con experiencia de trabajo en tierras bajo riego en su provincia natal-. Dicha concesión caducó tres años después por dificultades técnicas y económicas enfrentadas por los adquirentes para su efectiva puesta en producción.

11 Cfr. Ockier, M. C., 1988: 314 y sgtes. También Vapnarsky, C., 1983: 169. 
De esta superficie, 10.000 ha fueron adquiridas al Estado Nacional por el entonces Cnel. Manuel Fernández Oro -participante en la expedición de 1879- en jurisdicción de las actuales comunas de Cipolletti y Fernández Oro. Otras 3.000 ha pasaron a manos del Gral. Enrique Godoy -en el área de la actual comuna de Cinco Saltos- y posteriormente constituyeron la Colonia "La Picasa"12.

Previa contrucción de un nuevo canal de riego en el año 1902, Fernández Oro subdividió y vendió parte de las tierras de su propiedad en parcelas de importantes dimensiones constituyendo la Colonia Lucinda. Dichas parcelas fueron adquiridas por destacados comerciantes y terratenientes ya radicados en la zona, como Luis J. Casterás, los señores González Larrosa, Germán Da Ponte Ribeiro, Marcial y Miguel Muñoz, Enrique Albistur y otros $^{13}$. Esta colonia, servida ya por el ferrocarril y solucionado el problema del riego, sería una de las primeras en iniciar los cultivos intensivos en el Valle. En 1911, al pasar las obras particulares de riego a la administración nacional, se empadronaron 3.161 ha de las cuales estaban cultivadas alrededor de 2.500 en manos de 28 propietarios o regantes. En 1920 la superficie cultivada se incrementó a 4.306 ha divididas entre alrededor de 90 regantes $^{14}$. Ello está indicando un proceso de progresiva subdivisión que guarda directa relación con el desarrollo de la fruticultura regional.

Las tierras del Gral. Enrique Godoy, por su parte, serían vendidas a Llames Massini, permaneciendo incultas hasta el año 1910 en que fueron adquiridas por la Compañía de Tierras del Sud S.A.-subsidiaria de la empresa ferroviaria homónima-, en coincidencia con la habilitación del canal hasta el futuro dique sobre el río Neuquén y el inicio de la construcción del mismo. Esta Compañía, cuyo Presidente fue José Percy Clarke, había comprado las mismas a \$30 la hectárea, comenzando la enajenación de las primeras chacras de la denominada Colonia "La Picasa" en el año 1913 al precio uniforme de \$ 600 la ha pagadero en 5 cuotas anuales del 10\% y una final, al terminar el quinto año, del 50\%. En 1921, la casi totalidad de estas tierras había sido vendida en pequeñas fracciones de 2 a 50 ha a inmigrantes españoles e italianos -en su mayoría trabajadores de las obras de irigación y ferro-

12 Cfr. Vapnarsky, C., 1983: 152.

13 Ministerio de Obras Públicas (en adelante M.O.P.), Dirección General de Irrigación (D.G.I.), Intendencia de Riego del Río Negro Superior, Memoria año 1919/20.

14 Ibidem. 
viarias-, que en conjunto constituyeron 150 familias que cultivaron una superficie superior a las $2.000 \mathrm{ha}^{15}$.

Un proceso distinto siguió la conformación de colonias en la margen derecha del mismo río Neuquén, donde las tierras aún fiscales fueron reservadas por el Poder Ejecutivo Nacional hasta su valorización por efecto de la construcción del dique en 1910. Finalmente, en el año 1922, se creó la llamada Colonia Sayhueque (Centenario) por iniciativa de técnicos y obreros empleados en las obras de construcción del dique. El significativo fraccionamiento de esta área no redundó, sin embargo, en una ocupación y puesta en producción efectiva hasta varios años después ${ }^{16}$.

Por su parte, las tierras ubicadas en la margen izquierda del río Limay, en su valle inferior, se mantuvieron incultas y en gran parte desocupadas desde su distribución original (Remate de 1885) hasta comienzos de siglo, cuando la llegada del ferrocarril a la estación Neuquén (1902) y el traslado de la capital del Territorio a ese mismo punto (1904) provocaron su acelerada valorización"1. Aprovechando tales circunstancias, Casimiro Gómez, influyente comerciante porteño y adquirente original, compró importantes superficies a Francisco Villabrille y Ramón López Lecube a partir del mismo año de 1904. Estas tierras, conjuntamente con las de Valentina Duclout darían lugar, a partir de 1915, a la conformación de las Colonias Nueva España y Valentina, respectivamente. Posteriormente, en 1919, se creó la Colonia Bouquet Roldán. Cada una de ellas abarcaba entre 500 y 700 ha distribuidas entre alrededor de 60 colonos, lo cual evidencia un fraccionamiento importante de las tierras donde por muchos años prevalecerían los cultivos hortícolas para consumo local, asi como un precario sistema de riego por elevación mecánica que agravaba las dificultades de los colonos. El área comprendida por estas colonias sería conocida como "Chacras Neuquén".

Al este de la Colonia Roca, por su parte, el proceso de subdivisión de la tierra se inició recién sobre fines de la década de 1920, como producto de la habilitación del último tramo del canal principal del sistema integrado de riego en el año 1928. Estos campos, ale-

15 Barcia Trelles, J., 1923: 18.

16 Al respecto, ver Morinelli de Cava, M. B., 1981.

17 Cfr. Maida de Minolfi, E., Directora, y otros, 1981. 
daños a las actuales comunas de Godoy, Villa Regina y Chichinales, habian sido concedidos por el gobierno nacional, en su gran mayoría, al ex Mtro. de Agricultura Manuel Marcos Zorrilla, antes de 1900, abarcando una superficie superior a las 17.000 ha de valle, de un total de 36.000 ha que se le habian adjudicado en el Territorio de Río Negro.

La primera subdivisión de estas tierras se produjo en 1924 cuando la Compañía Italo Argentina de Colonización (CIAC) compró 5.000 ha con el propósito de poblarlas con colonos procedentes de Italia, en la denominada Colonia Villa Regina. Este proyecto colonizador estaba auspiciado por la embajada italiana en la Argentina, los Bancos de Italia y Río de la Plata, el Banco Francés e Italiano para la América del Sud y cinco compañías navieras italianas radicadas en Buenos Aires ${ }^{18}$. La CIAC inició inmediatamente un importante fraccionamiento en lotes de 10 a 15 ha, entregando las chacras progresivamente a los colonos desde 1925, facilitándoles créditos mensuales para atender las primeras necesidades. Las chacras se entregaban alambradas, con canales y casa reglamentaria de mampostería y barro, mejoras que se incluían en el precio total de venta que oscilaba entre $\$ 1.000$ y $\$ 1.200$ la ha. El pago de la tierra se hizo mediante préstamos de colonización otorgados por el Banco Hipotecario Nacional, que los colonos debían pagar a la Compañía en porcentajes anuales hasta la cancelación definitiva al cabo de cinco años. Un relevamiento de estas colonias en el año 1928 informaba de las dificultades presentadas a la mayoría de los colonos para afrontar el pago de la deuda, amortización e intereses, logrando sólo prosperar en estos primeros años aquellos que habían contado con algún capital inicial ${ }^{19}$.

Otras 5.000 ha de los "campos de Zorrilla" -alrededor de la actual comuna de Godoy-, fueron adquiridas por el médico español Avelino Gutiérrez en 1920 y su yerno, el matemático Julio Rey Pastor, en 1930. Ambos propietarios, radicados en Buenos Aires, las explotarían parcialmente por administración procediendo a subdividirlas y venderlas en épocas muy posteriores. Las tierras que abarcan el extremo oriental del Valle hasta Chichinales eran también de propiedad de la Suc. Zorrilla, Gutiérrez, Rey Pastor y Suc. Cayetano Rodríguez. Todas ellas permanecieron indivisas en grandes explotaciones dedicadas al cultivo extensivo de alfalfa hasta alrededor de la década de $1950^{20}$.

18 Río Negro. Pasado y Presente, Ed. Crismar, Viedma, 1980: 238.

19 Cfr. Goti, A., 1928.

20 Cfr. Vapnarsky, C., 1983: 177. 


\section{Distribución espacial de la pequeña explotación}

De lo expuesto anteriormente se desprende que la aparición del agente económico que nos ocupa estuvo directamente ligada al proceso de subdivisión de las grandes propiedades, proceso que se concretó, según vimos, en distintas etapas en las diferentes áreas del Alto Valle. Es así como, en el transcurso de la década de 1910, las colonias ubicadas hacia el Oeste del mismo, particularmente las denominadas Lucinda, La Picasa y zona Chacras Neuquén, constituirían los primeros ejemplos de fraccionamiento en parcelas menores -especialmente las dos últimas- definiendo la más temprana aparición de pequeños productores propietarios. Idéntico proceso se observaría sobre fines de la década de 1920 hacia el Este de la misma región productiva, centrado casi exclusivamente en las áreas de Allen, General Roca y Colonia Villa Regina, y en directa relación con su incorporación al sistema integral de riego.

La importante presencia de explotaciones entre 1 y 10 ha es ya observable en las áreas mencionadas hacia 1927, según demuestran los Cuadros $\mathbf{N}^{\circ} \mathbf{1}$ y 2. Cabe acotar que el criterio de división en zonas utilizado en los mismos corresponde al aplicado por la Intendencia de Riego del Río Negro Superior en sus registros estadísticos. Dichas zonas equivalen a distritos de riego y abarcan respectivamente las áreas de Cinco Saltos (zona I), Cipolletti y Fernández Oro (zona II), Allen y General Roca (zona III), Cervantes e Ingeniero Huergo (zonas IV a VII) y Godoy a Chichinales (zonas VIII a XVIII). Surge claro del capítulo anterior que las zonas I, II y III estarían reflejando mayoritariamente el peso del temprano parcelamiento de las colonias La Picasa, Lucinda y las áreas de Allen y General Roca, respectivamente. La zona VIII a XVIII refleja, por su parte, la incidencia mayoritaria del parcelamiento de la Colonia Villa Regina.

De este modo, en el Cuadro $\mathbf{N}^{\circ} \mathbf{1}$ puede observarse cómo las explotaciones de 1 a 10 ha constituían el $37 \%$ del total de explotaciones en la zona I, el $38 \%$ en la Zona II y el $42 \%$ en la zona III. En ésta última, sin embargo, las explotaciones de 50 a 100 ha representaban el $18 \%$ del total y en la zona IV a VII el 35\%, lo cual estaría indicando que en estas áreas las explotaciones de mayor tamaño tenían hacia 1927 una importante incidencia. Ello puede vincularse directamente, como luego veremos, a los cultivos dominantes en las mismas. Por último, la zona de Chacras Neuquén reflejaba asimismo una importante participación de las explotaciones de 1 a 10 ha (48\%). Llama la atención en este caso la incidencia de las explotaciones menores de 1 ha (27\%), lo que podemos inferir refleja la ya mencio- 
nada condición de horticultores de sus primeros colonos. Información correspondiente al año 1928 -inmediatamente después de la incorporación del área al sistema de riego- nos permite apreciar en el Cuadro $\mathbf{N}^{\circ} \mathbf{2}$ la evolución del fraccionamiento ya mencionado para el caso de la zona VIII a XVIII, siendo necesario tener presente que las unidades de explotación menores correspondían casi exclusivamente a la Colonia Villa Regina, en tanto que las superficies mayores se localizaban en el resto del área en la que aún predominaban hacia esa fecha, como se verá, los cultivos extensivos. Así, las explotaciones entre 1 y 10 ha concentraban el $21 \%$ del total en tanto que las de 50 a 100 ha constituian el $49 \%$ y las superiores a 100 ha el $8 \%$.

Podemos concluir de las cifras analizadas que ya en las décadas de 1910 y 1920 la superficie promedio de los establecimientos era menor en el extremo Oeste del valle y aumentaba progresivamente hacia el Este, indicando modalidades diferenciadas de uso de los recursos en función de cultivos preferenciales, lo que podrá observarse en el apartado siguiente.

En el Cuadro $\mathbf{N}^{\circ} 3$ mostramos, para los años 1946/47 -fin de la etapa en estudioel estado de situación con referencia a la superficie de las explotaciones en las distintas zonas. En él observamos que la tendencia anteriormente señalada se mantiene con referencia a la supervivencia de las explotaciones de mayor superficie-entre 50 y 100 ha- en las zonas III, IV a VII y VIII a XVIII; en tanto que se refleja un incremento importante de la subdivisión en pequeñas explotaciones - 1 a 10 ha- en el Oeste del valle $(66 \%$ zona l; $53 \%$ zona II; $51 \%$ zona III y $51 \%$ zona Chacras Neuquén) que se ha extendido, aunque en menor proporción, al resto del área (30\% zona IV a VII y 35\% zona VIII a XVIII). Nótese asimismo el generalizado aumento de las chacras de 1 a 5 ha, que aparecen como las más representativas dentro del estrato de 1 a 10 ha, lo cual permite inferir la rentabilidad de estas explotaciones en el transcurso de la etapa. Es evidente que, con la evolución operada en la actividad frutícola hacia estos años, el agricultor propietario de pequeñas parcelas se había afianzado como sujeto social y agente económico preponderante en todo el Alto Valle. Resulta significativo que las cifras anteriores sean aproximadas a las que se registran en censos más actuales -como el de 1974 señalado oportunamente en la introducción-con lo cual se demuestra que la estructura parcelaria se definió en la etapa que nos ocupa. 


\section{De la alfalfa a la frutiviticultura: Los ciclos productivos en el Alto Valle}

La necesidad de obtener rápidos ingresos que permitieran afrontar los gastos iniciales de producción llevó a los primeros colonos, siguiendo el ejemplo de las grandes propiedades establecidas en el valle, a practicar mayoritariamente el cultivo de alfalfa y, en menor escala, otros cultivos anuales como cereales y leguminosas. La plantación de alfalfa, aún en las colonias más fraccionadas, aparecía como ventajosa en función del corto ciclo productivo, los seguros resultados de la explotación, su resistencia a los cambios climáticos, la fácil colocación en los mercados (demanda para pasturas locales y en la zona sur de la Pcia. de Bs. As., exportación de semillas a EE.UU, etc.) y los buenos precios obtenidos, siendo además necesario su cultivo inicial para nitrogenar la tierra. La relativa disponibilidad de capital derivada de esa actividad fue destinada a una incipiente plantación de viñas y frutales que rodeaban la vivienda familiar con destino al consumo propio, todavía sin criterio comercial$^{21}$. Es asi como, hacia fines de la década de 1910, no se habian logrado cultivos intensivos en áreas bajo riego siendo aún escasa la subdivisión de la tierra y la inversión de capital. La presencia de cultivos mixtos era, según las fuentes de los años 1919-20, predominante aún en las áreas más subdivididas como en la Colonia La Picasa que registraba 665 ha destinadas a la producción de pasto y semilla de alfalfa, 99 ha a vid y 14 ha a frutales, siendo asimismo importante el cultivo de legumbres y hortalizas -387 ha- ${ }^{22}$.

Concluída la primera etapa de las obras de irrigación -dique sobre el río Neuquén en 1916- comenzó a producirse, sobre inicios de la década de 1920, el cambio productivo que diez años más tarde haría de la fruticultura el cultivo por excelencia en el Alto Valle. Un rol preponderante en ello cumplió la empresa del Ferrocarril Sud que financió poco más del $50 \%$ del costo inicial de las obras de dique y construyó, por contrato con el gobierno nacional, la red de canales y desagües que completarían el sistema integral de riego años más tarde. A cambio de ello, la empresa recibió títulos nacionales denominados "bonos de irrigación" que devengarían un interés anual del 5\% y serían cubiertos por el gobierno mediante el cobro de un canon de riego a los beneficiarios ${ }^{23}$.

21 Cfr. Mac Donald, J., 1939.

22 M.O.P., D.G.I., Memoria anual 1919/20.

23 Regind, W., 1929: 45 y 51. 
Simultáneamente la empresa británica encargó en 1918 al Ing. Agrónomo José Barcia Trelles la instalación y dirección de una Estación Experimental en el área de Cinco Saltos. Esta chacra se destinó al ensayo de cultivos, con la especial misión de incrementar la producción en el Valle para intensificar el transporte. Importantes genetistas y fitopatólogos como el Ing. Enrique Rowland Amos y Jaime Mc Donald trabajaron en esta Estación, que importaba y reproducía en sus viveros variedades elegidas de frutales injertados para su venta a plazos con precios de fomento a los fruticultores, a la vez que sus técnicos sugerían, en publicaciones de acceso gratuito al productor, la conveniencia económica de trabajar la tierra en pequeñas fracciones de hasta 10 ha para permitir el cultivo intensivo de las mismas en explotaciones familiares, dando preferencia al frutal. De esta manera planteaban la reducción en los costos de explotación al prescindirse de la contratación de mano de obra asalariada ${ }^{24}$. Resulta evidente el interés demostrado en la reconversión productiva regional y el rol adjudicado en ella a las pequeñas explotaciones, lo cual se explica en función de la planificación conjunta de la actividad por parte de los capitales británicos, como luego se verá en el tratamiento de los actores sociales.

Las fuentes analizadas coinciden en señalar hacia mediados de la década de 1920 un rápido desalojo de la alfalfa por los viñedos y frutales. Si bien el cultivo de la primera aparece estable en esos años (1923/24: $142.000 \mathrm{tn}$ y 1926/27: $138.000 \mathrm{tn}$ ) cabe acotar que ello se debe a la incorporación de nuevas áreas bajo riego lo que supone un sembrado necesario con alfalfa para preparación del suelo. Hacia 1930 la producción de alfalfa disminuyó en una cantidad superior a las 30.000 tn respecto al año anterior, baja que se repitió para 1931 cuando se despachó por ferrocarril sólo el 40\% del total producido a causa de los bajos precios y las dificultades de venta ${ }^{25}$. De las cantidades que quedaron en la zona, la parte no consumida se destinó a semilla por su mejor conservación, surgiendo dos plantas de molienda en Ing. Huergo que exportaban su producción a EE.UU. con destino a la elaboración de alimentos para aves, las que dejaron de funcionar definitivamente hacia fines de la década.

Paralelamente a este proceso, se fueron intensificando las plantaciones de viñedos y frutales en los campos más fraccionados como La Picasa y la zona colonizada por la CIAC

24 Cfr., por ejemplo, Barcia Trelles, J., 1923 y Conti, E., 1932.

25 M.O.P., D.G.I., Memoria anual 1931/32. 
en Villa Regina, donde predominaban los pequeños propietarios con trabajo familiar, derivando en un incremento del valor de la tierra en comparación con las áreas donde perduraban importantes extensiones en las que subsistía el cultivo de alfalfa ${ }^{26}$. Por otra parte, la relación entre toneladas producidas y rendimiento en precio de la producción de alfalfa y frutas muestra ya una diferencia sustancial a favor de éstas últimas ${ }^{27}$.

Las siguientes cifras abonan lo sostenido respecto a la evolución de la superficie plantada con frutales y viñedos, indicando para el año agrícola 1923/24 la presencia de 456 ha y 1.850 ha para cada cultivo, las que aumentaron hacia $1926 / 27$ a 1.431 ha y $3.255 \mathrm{ha}^{28}$, respectivamente. Ello refleja en tres años un incremento para viñedos del $80 \%$ y para frutales del 310\%, porcentajes que continuaron aumentando año a año. Tal evolución se corrobora en el incremento de la participación de estos productos en el total de cargas despachadas por ferrocarril observable a partir de los años 1926/27, fechas altamente representativas respecto al cambio productivo que nos ocupa por cuanto implican la duplicación del volumen de frutas despachado respecto al año 1923/24 (Ver Cuadro N 4). A partir de esa fecha, y abonando también la definición del perfil productivo regional hacia 1930, las cargas consignadas como "frutas y legumbres" -de las cuales las primeras eran sin duda las más significativas- muestran una clara tendencia ascendente que en 1931 representó el $11 \%$ del total, alcanzando una participación del $40 \%$ en 1940 y superando en el transcurso de esa década el $60 \%{ }^{29}$. Nótese, en el mismo Cuadro $\mathbf{N}^{\circ} \mathbf{4}$, que las toneladas de pasto en fardo transportadas por ferrocarril aumentaron en cifras absolutas hasta el año 1928, comenzando luego una progresiva e importante disminución hasta hacerse irrelevantes a comienzos de la década de 1940. Esto último atribuíble a los bajos precios de la alfalfa enfardada, a la disminución de la demanda en función del desarrollo del transporte automo-

26 En el año 1927, el valor de la ha en superficie regable en las zonas I y II (Lucinda y Picasa) era de \$1.040, en tanto que en la zona III (Allen a General Roca) era de \$790, y en la zona IV a VII (Cervantes a Ing. Huergo) de $\$ 810$ (M.O.P., D.G.I., Memoria anual 1926/27).

27 Datos de 1926 lo confirman cuando señalan para 18.379 tn de alfalfa un precio total de $\$ 404.338$ y para 2.032 tn de frutas, $\$ 538.640$ (Ibidem).

28 M.O.P., D.G.I., Memoria anual 1928/29.

$29 \mathrm{El}$ inicio del uso de camiones como medio de transporte permite suponer la ampliación de esas cifras, aunque en términos poco significativos dada la precariedad y reducida capacidad de los mismos, que no constituyeron una competencia seria al transporte ferroviario hasta después de la etapa en estudio. 
tor y del abandono de la caballada como forma de tracción, y al cierre del mercado de EE.UU. para la producción de semilla. A partir de los años 1930 la mayor cantidad de alfalfa enfardada fue aportada por la zona de riego nuevo (al Este de la Colonia Roca), según se desprende del análisis pormenorizado de las cargas despachadas por ferrocarril en cada una de las estaciones ${ }^{30}$. Este es otro dato estadístico que corrobora lo sostenido respecto a que hay una relación directa entre la llegada del riego a esa zona en 1928, el tardío fraccionamiento de las tierras en función de ello y su más lenta incorporación al cultivo intensivo.

Podemos concluir, en resumen, que la reconversión productiva en el Alto Valle fue un proceso lento y gradual que se inició en las áreas más fraccionadas ocupadas por pequeños productores propietarios a lo largo de la década de 1920, definiéndose como ciclo básicamente frutícola alrededor de los años 1930, habiendo cumplido en ello un rol fundamental el capital británico en su búsqueda de un cultivo intensivo que volviese mas redituable el transporte. Paralelamente, se habría ido produciendo el agotamiento del ciclo de la alfalfa. Sin embargo, la superficie destinada a este último cultivo siguió siendo representativa en la totalidad del valle hasta finales de la década de 1940, según puede observarse en el Cuadro $\mathbf{N}^{\circ} \mathbf{5}$. Ello se explica en función de la señalada supervivencia de propiedades de significativas extensiones en la zona Este del mismo que permanecieron indivisas hasta esos años.

La viña por su parte tuvo, desde el inicio del cambio productivo aludido una significativa incidencia -atribuible entre otras causas a su inferior ciclo productivo ( 3 años) con respecto a peras y manzanas- que puede extenderse hasta mediados de la década de 1930, período durante el cual superó incluso en superficie cultivada a los frutales, siendo ésta una característica común a todas las áreas tempranamente fraccionadas. La disminución de la superficie cultivada, observable a partir de 1935 (Ver Cuadro $\mathbf{N}^{\circ}$ 5), puede atribuírse, según fuentes consultadas, a la presión impositiva ejercida por el Estado Nacional sobre el vino elaborado y al accionar de la Junta Reguladora de Vinos, a lo cual aparentemente se sumó una importante oposición de los bodegueros cuyanos ${ }^{31}$. En el mismo Cuadro puede ob-

30 La misma información contenida en el Cuadro $\mathbf{N}^{\circ} 4$ se relevó para cada una de las estaciones ferroviarias del Alto Valle, información que no se incluye en el presente trabajo por razones de espacio.

31 Este tema, mencionado en las fuentes primarias consultadas, no ha podido ser a la fecha suficientemente analizado a los fines de su corroboración. Sin embargo, la importan- 
servarse como los frutales -peras y manzanas- presentan un crecimiento gradual y sostenido a lo largo de la etapa que nos ocupa. Un proceso similar en la evolución de los distintos cultivos se evidencia en el área denominada Chacras Neuquén, siendo en este caso muy representativa la superficie cultivada con hortalizas.

\section{Caracterización de actores sociales}

Habiendo descripto anteriormente el proceso de subdivisión de la tierra que dio origen al surgimiento de las pequeñas explotaciones agrícolas en el Alto Valle y su localización espacial, así como el cambio productivo que hizo de la fruticultura la actividad principal en la región, cabe ahora definir del conjunto de actores sociales vinculados al subsistema frutícola, aquellos que en su primera etapa se constituyeron en los más relevantes. Ello implica considerar básicamente al pequeño productor propietario como actor más generalizado y, en forma global, a los agentes vinculados al proceso de elaboración -empaque e industria- y al proceso de comercialización y transporte. Estos últimos en función de su relación con el anterior y las consecuentes posibilidades de acumulación del mismo.

Aunque definidos los productores primarios más generalizados como pequeños, sobre la base de la reducida superficie de sus explotaciones -1 a 10 ha- y el predominio del trabajo familiar, cabe acotar que por tratarse de un cultivo intensivo esas condiciones eran consideradas óptimas en la época para el máximo rendimiento y rentabilidad de la unidad productiva. El capital inicial con que el agente que nos ocupa encaró los ciclos productivos fue reducido, debiendo recurrir en los primeros años, según vimos, a la plantación de cultivos mixtos (alfalfa-vid-frutales) además de hortalizas y legumbres para el consumo familiar, tratando de obtener rápidos beneficios que le permitiesen cubrir la inversión inicial.

Cabe recordar, por otra parte, que este productor accedió a su explotación mediante la compra a particulares y/o compañías de colonización en momentos en que ya las tierras del valle se habían valorizado notablemente por efecto de las obras de riego y la llegada del ferrocarril. Los primeros propietarios, adjudicatarios como vimos de grandes extensiones adquiridas al Estado a precios preferenciales en virtud de las leyes de colonización vigentes $-\$ 2,50$ la ha-, subdividieron y vendieron sus tierras a precios sensiblemente mayores. Se pueden mencionar, como ejemplos, el precio uniforme de $\$ 600$ la ha exigido

cia đề mismo amerita su posterior tratamiento en el curso de la ìnvestígación. 
por la Compañía de Tierras del Ferrocarril Sud a los colonos de "La Picasa" sobre mediados de la década de 1910, así como el precio promedio de $\$ 1.200$ la ha que abonaron los colonos de la CIAC en Villa Regina en 1925. Informes del año 1928 daban cuenta del excesivo aumento operado en el valor de las tierras del valle cuando por el excelente rendimiento de las mismas sólo podía justificarse un precio promedio de $\$ 600$ la ha ${ }^{32}$. Estas apreciaciones se ven ampliamente confirmadas si comparamos con los precios a que se ofrecían campos a la venta en la Pcia. de Buenos Aires en publicaciones de esa fecha. Los mismos oscilaban entre $\$ 100$ y $\$ 300$ la ha en los Partidos de Las Flores, Tres Arroyos y Ayacucho ${ }^{33}$.

En general, las facilidades concedidas al colono para el pago de su parcela no excedían, según vimos, los cinco años de plazo, lo cual implicaba una deuda inicial que debía ser amortizada en un lapso de tiempo relativamente corto. A ello se sumaban los gastos iniciales de manutención familiar y de inversión en la explotación, cubiertos en la mayoría de los casos por préstamos de colonización del Banco Hipotecario Nacional gestionados por los propietarios originales o las propias compañías colonizadoras. Cabe acotar que esta institución sólo acordaba créditos sobre tierras emparejadas y con canales, imponiendo a los compradores la condición de iniciar, dentro del primer año, la plantación de vid y frutales junto con alfalfa para el nitrogenado inicial de la tierra ${ }^{34}$.

Según la disponibilidad inicial de recursos existieron productores que con capital propio instalaron y sostuvieron la chacra hasta su puesta en producción plena, en tanto otros debieron recurrir necesariamente al crédito. Era frecuente que antiguos pobladores de la zona que habían logrado acumular un mínimo de capital en otras actividades se convirtieran en productores. Tal fue el caso de destacados vecinos de la antigua Colonia Roca, técnicos y obreros intervinientes en la construcción de las obras de riego y ferroviarias, dueños de tropas de carros y comerciantes reconocidos en la región. También trabajadores agrícolas de provincias como San Juan y La Rioja que se ocuparon de las tareas de desmonte y nivelación en los primeros establecimientos, siendo recompensados con tierras en algunos casos o logrando adquirirlas en otros.

32 Cfr. Goti, A., 1928.

33 Avisos varios de venta de campos ofrecidos en Revista del Ferrocarril del Sud, diciembre 1929.

34 Información al respecto brinda Alfredo Goti, Vice Presidente del Banco Hipotecario Nacional, en Goti, A., 1928. 
Por otra parte, grupos seleccionados de familias agricultoras inmigrantes como es el caso de los italianos de Villa Regina y de los judíos de Rusia instalados al Este de la Colonia Roca, debieron soportar condiciones de vida especialmente duras a causa del endeudamiento y la lentitud del ciclo productivo del frutal que requería 6 años antes de comenzar a cubrir los gastos anuales y amortizar el capital invertido ${ }^{35}$. Ello explica la necesidad de ampliar los ingresos del grupo familiar durante estos primeros años, siendo frecuente que el productor se viera obligado a vender su fuerza de trabajo desarrollando complementariamente tareas asalariadas en calidad de peón o como arrendatario o mediero, sobre todo en las parcelas destinadas al cultivo de alfalfa o vid, donde las dos últimas formas de explotación eran más comunes ${ }^{36}$.

Alrededor de los años 1928/30 se habría producido un significativo punto de inflexión. El actor social caracterizado, mediante el cultivo inicial de alfalfa y el trabajo extrapredial, había logrado financiar la reconversión productiva de su pequeña explotación familiar. A ello se sumaron el organizado sistema de comercialización de la fruta creado por los capitales ingleses, las excelentes condiciones de precios y el constante aumento de la demanda externa, así como la ausencia de competidores en el Hemisferio Sur. De este modo, el pequeño productor valletano comenzó a representar hacia 1930 un importante papel en la generación de excedentes, participando en alguna medida de la acumulación del mismo, lo que le habría posibilitado acceder a las nuevas tecnologías existentes en el mercado.

Avanzada la década de 1930, estos pequeños productores habrían dejado de funcionar como economías estrictamente familiares, ajustando su comportamiento a una racionalidad de caracter mas capitalista, en el sentido de maximizar el rendimiento de su unidad productiva y, por lo tanto, su beneficio económico, adaptándose a las exigencias del mercado mediante la incorporación de tecnología, la definición varietal del monte y la conformación de diversos tipos de asociaciones. Esto último, con el objeto de modificar su poder de negociación y lograr el peso necesario al concertar la comercialización, orientar a su

35 Esto en las condiciones técnicas de la época -conducción libre en monte abierto- donde la producción plena del monte frutal se lograba a los 10 años con 24 de vida útil estimada. Cfr. al respecto Conti, E., 1932.

36 Existían en la época condiciones de aparcería y arrendamiento muy variables, siendo más utilizados como sistemas de explotación en las áreas alfalfadas. Su tratamiento excede los alcances de esta primera aproximación a la temática. 
favor el crédito y las inversiones del Estado, así como facilitar la transferencia de tecnología. Citemos como ejemplo, hacia 1934, la existencia de una serie significativa de asociaciones de productores como la Cooperativa Frutivinicola Allen Ltda., Chacareros Unidos Coop. Industrial y Productores Cipolletti, Fruticultores de Colonia Lucinda, Fruticultores de Cinco Saltos, Cooperativa Reginense, etc. ${ }^{37}$.

Estas cooperativas de productores habrían intervenido asimismo activamente, aunque en condiciones precarias, en el proceso de transformación de la fruta post-cosecha, estableciendo galpones de empaque y bodegas en las distintas zonas del Valle. Estas últimas habían alcanzado, hacia el año 1940, un desarrollo considerable. La estadística de industrias de la Dirección General de Irrigación señala para esos años la existencia de 10 galpones de empaque y 36 bodegas en las zonas I y II; 55 bodegas en la zona III; 17 bodegas en la zona IV a VII; 21 bodegas en la zona VIII a XVIII y 3 galpones de empaque y 6 bodegas en la zona Chacras Neuquén ${ }^{38}$. Evidentemente, el desarrollo del cultivo de la vid provocó un importante incremento en la fabricación de vino. Muchas de las bodegas registradas eran propiedad de pequeños productores que efectuaban la elaboración en las propias chacras, en forma muy rudimentaria, con destino al consumo propio y local. Sin embargo, se destacan algunas bodegas importantes de antigua trayectoria como la de Humberto Canale en Gral. Roca, instalada desde el año 1913, y la de Patricio Piñeiro Sorondo en Allen, que bajo el nombre de "Barón de Río Negro" produjo desde el año 1912 vino de reconocida calidad consumido en todo el país y desde 1939 el champagne "Baronet" que alcanzó fama internacional ${ }^{39}$. Se ha podido contabilizar asimismo, para esos años, un total de 10 secaderos de fruta en distintos puntos del Valle, con escasas instalaciones y producción en pequeña escala destinada al consumo local.

La mayoría de los galpones de empaque mencionados pertenecían a las ya referidas cooperativas de productores que de manera muy primitiva efectuaban la clasificación y embalaje de la fruta. Con referencia a este tema debe destacarse nuevamente el rol del capital británico. En el año 1928, la compañía del Ferrocarril Sud envió al Ing. Amos a Es-

37 M.O.P., D.G.I., Memoria anual 1934/35.

38 M.O.P., D.G.I., Estadística de las Industrias. Su producción y valor, años 1940/42.

39 "El Barón de Río Negro y el nostálgico recuerdo del Baronet", art. en Diario Río Negro, 25-5-1989. 
tados Unidos para estudiar y organizar la explotación y comercialización de la fruta, el transporte ferroviario y la conservación frigorífica. Alli se contrataron expertos en fruticultura bajo riego, empaque y comercialización, que formarían parte de la nueva empresa dependiente del ferrocarril, la Argentine Fruit Distributors (A.F.D.) que desde ese mismo año instaló plantas de empaque en puntos estratégicos del Alto Valle (Estaciones de Cinco Saltos, Cipolletti, Allen، J.J. Gómez y Villa Regina) donde se realizaba la clasificación atendiendo al tamaño y la calidad de la fruta, incorporando moderna tecnología para la tipificación y embalaje adecuados, además de organizarse la venta en Buenos Aires y en Europa. Esta empresa no compraba la fruta, recibiéndola sólo en consignación, clasificándola y embalándola para luego despacharla a Buenos Aires, abonando a los fruticultores los precios obtenidos previo descuento de los gastos, fletes y comisión ${ }^{40}$. Simultáneamente funcionaron filiales de la A.F.D. en otras áreas fruticolas servidas por líneas férreas (Central de Entre Ríos y Trasandino por Mendoza), con lo cual las empresas ferroviarias se aseguraron un importante papel en la comercialización y el monopolio absoluto del transporte de frutas, repitiendo así lo ya efectuado en el área del cereal y apropiándose de gran parte de los excedentes generados en las zonas productivas más importantes del país.

Hasta el surgimiento de esta firma, la comercialización en el Alto Valle se efectuaba de manera muy rudimentaria, mediante la presencia de compradores externos a la región, con cuadrillas de embaladores que trabajaban directamente en las chacras, sin mayores cuidados en el manejo de la fruta. La AFD modificó sustancialmente las formas precarias de comercialización y acceso a los mercados, impulsando la significativa exportación de frutas del Alto Valle a partir de los años $1930^{41}$. Hacia 1935, la A.F.D. se imponía como empresa de clasificación y empaque con importante incidencia en el mercado de trabajo local.

A la modernización del proceso de transporte y venta se sumó el interés de la empresa del Ferrocarril Sud por mejorar la producción, tarea que, según vimos, se efectuaba

40 Cfr. Mac Donald, J., 1939.

41 La AFD impuso tempranamente en la zona la utilización del "cajón perdido" en reemplazo de los envases de retorno, a los efectos de la defensa sanitaria de las plantaciones. Esta modalidad se convertiría luego en una exigencia oficial de la Dirección de Contralor de la Producción Frutícola, con lo cual se logró la standarización de los envases. Esto provocó la aparición de aserraderos en la región, como una industria derivada de la fruticultura, cuyo número alcanzaba en 1940 a 25 (M.O.P., D.G.I., Estadistica de las Industrias. Su producción y valor, 1940/42). 
desde 1918 a través de la Estación Agronómica de Cinco Saltos que en el año 1930 pasó también a depender de la A.F.D.. A los ensayos de cultivos en viñas y frutales para determinar la reducción a las variedades de mejor adaptación, se agregó la venta de plantas a crédito, el apoyo técnico y la provisión gratuita al productor de equipos mecánicos de pulverización, remedios y fertilizantes. Un equipo de expertos recorría permanentemente el valle para asesorar al productor en prácticas culturales adecuadas, como por ejemplo la poda y el control de plagas, editándose una circular de distribución gratuita entre los productores, Ilamada "Sugestiones Oportunas". Se importaron máquinas curadoras y modernas pulverizadoras y se organizó un servicio muy eficiente de reparación. De esta manera la empresa ferroviaria apoyó sistemáticamente a la fruticultura regional, impulsando la generalización de un monocultivo que ante la disminución del valor comercial de la alfalfa le asegurase ganancias permanentes a través del monopolio ejercido en el transporte y la comercialización. Se incrementó a ese fin el número de estaciones de ferrocarril en las zonas de regadío hasta un total de 18 en 1929 (una estación cada 7 km) ${ }^{42}$.

A medida que la fruticultura se fue afianzando como actividad dominante, produciendo la cantidad y calidad que los mercados requerian, la A.F.D. fue gradualmente desinteresándose de los aspectos productivos, centrando sus esfuerzos en el empaque y la comercialización. Todo ello en función de la rentabilidad que suponía para los capitales británicos -bajo la forma de fletes- el monopolio absoluto de los transportes como medio más directo de apropiarse del excedente generado por la actividad en la etapa que nos ocupa. Probatorio de lo anteriormente dicho son los continuos reclamos de los productores y comerciantes por la incidencia de los altos fletes ferroviarios que llegaban a duplicar el valor del producto, encareciendo notablemente su precio final. Valga como ejemplo que, en 1935 , un cajón de peras puesto en Buenos Aires valía $\$ 4,75$, de los cuales $\$ 3,40$ eran gastos de comercialización y transporte y, entre ellos, $\$ 1$ de flete por cajón $n^{43}$.

La A.F.D. significó el surgimiento en la etapa de un actor social adicional que, sin intervenir en forma directa en la producción, buscó acceder al valor generado por los sujetos sociales propiamente agrarios estableciendo diversos tipos de vinculaciones. Es así como, hasta el año 1948 en que la firma inglesa desapareció por la nacionalización del ferro-

42 M.O.P., D.G.I., Memoria anual 1928/29.

43 Corporación Frutícola Argentina, Revista Oficial، Año , N 9, sept. 1935: 19-20. 
carril, el capital comercial británico controló la producción sin intervenir directamente en ella. A los efectos de asegurar un alto margen de ganancia, estimuló el surgimiento de pequeñas explotaciones, financiando parcialmente su organización productiva y capacitándo a los productores en las técnicas del nuevo cultivo. De esa manera, renunciaba a la integración vertical de la actividad pero monopolizaba su transporte y establecía un sistema organizado de comercialización, convirtiéndose, en suma, en el sector dominante que condujo la direccionalidad del proceso productivo en el Alto Valle.

\section{Los mercados y la comercialización de la fruta}

Resta analizar, por último, el destino final de la producción frutícola. Hacia mediados de la década de 1930 el ritmo de la misma comenzó a superar la capacidad de absorción del mercado interno y externo que hasta ese entonces era muy limitado, motivando una especial preocupación por la obtención de nuevos mercados. Ello se refleja, entre otras cosas, en el accionar de la Corporación Frutícola Argentina creada en 1935 con el principal objeto de incentivar la ampliación de la demanda externa. La misma, con sede en la Capital Federal, agrupó a los más representativos productores del país y a grandes firmas de comerciantes mayoristas -exportadoras e importadoras- como Elio Filomena, José Peluffo, Diego Piñeiro Pearson y Humberto Canale, todos ellos con una importante presencia en las distintas ramas de la actividad dentro y fuera del Alto Valle. Cabe destacar que los empresarios mencionados eran, además de muy importantes productores, propietarios de galpones de empaque en la región y de casas de comercio mayoristas y de exportación en Buenos Aires, siendo los únicos ejemplos localizados de integración vertical de la actividad para esta etapa. Resulta obvio que sólo los más grandes productores pudieron escapar al control comercializador de la A.F.D., aunque no así al pago de los fletes impuestos por el monopolio ferroviario. El pequeño productor, con menor capacidad de acumulación, no tuvo mayores alternativas para canalizar su producción sino a través de la empresa de capitales ingleses.

Hacia 1930, coincidentemente con la modernización del sistema de comercialización impuesto por la AFD, se inició la exportación de frutas frescas procedentes de la región, siendo la pera en su variedad Williams el primer producto comercializado en los mercados externos -principalmente Inglaterra, Brasil y Francia y en ese orden de importancia-, situación que se mantuvo hasta 1936 en que la manzana comenzó su participación en el volumen exportado a Francia, Brasil y Suecia. Del total de ese volumen, 25.175.606 tn en 1936, 
el $80 \%$ estaba integrado por peras y uvas, en tanto que el $20 \%$ restante era cubierto por la manzana que debía competir con la importante exportación australiana a los mercados europeos. De ese $20 \%$, el $75 \%$ lo constituian manzanas procedentes del Alto Valle de Río Negro y Neuquén, siendo del mismo origen el $72 \%$ de las peras exportadas. La uva, en tanto, reflejaba el exclusivo monopolio exportador de la zona cuyana ${ }^{45}$.

Hacia 1935/36 se alcanzaron cifras récord en la exportación de frutas frescas ocupando Río Negro el primer puesto en volumen de producción nacional -seguida por Mendoza- ${ }^{46}$, cifras que continuaron incrementándose hasta el estallido del conflicto bélico mundial en 1939. En esos años, Argentina ya exportaba a un conjunto de 18 países europeos y a Brasil y EE.UU. en el continente americano.

El significativo aumento de la producción en función de la demanda externa acrecentó las preocupaciones por solucionar los problemas derivados de la deficiente industria frigorífica nacional, motivando intentos experimentales para la conservación de la fruta. Hacia 1938 no existian aún frigoríficos para preenfriado en las zonas de producción, situación que hasta donde hemos podido observar se mantuvo durante toda la etapa analizada. Sólo Buenos Aires contaba con algunos frigoríficos que poseían una capacidad de almacenamiento muy reducida ( 2.800 .000 cajones tipo standard $)^{47}$. Tratando de captar parte del volumen exportado del área de Río Negro, se produjo sobre fines de la década de 1930 la habilitación del Puerto Galván en Bahía Blanca por el cual se realizó el primer embarque experimental de peras a Europa en $1938^{48}$. Simultáneamente a ello se le concedió a la Sociedad de Agentes Distribuidores de Frutas Argentinas la autorización para el funcionamiento en dicho puerto del Frigorífico "Los Cuatreros" 49 . De este modo se abriría para los productores valletanos una importante posibilidad de abaratar costos. Sin embargo, el

45 Datos de elaboración propia sobre información estadística de la Memoria de la Dirección de Contralor de la Producción Frutícola, Mrio. de Agricultura de la Nación, 1936.

46 Sirva como ejemplo el incremento producido en la exportación de peras, en tanto rubro principal en esta etapa, que de 3.700 cajones en 1931 llegó a 238.000 en 1935 (Revista de la Corporación Frutícola Argentina, Año II, No 19, julio 1936).

47 Corporación Frutícola Argentina, Revista Oficial, Año IV, N 42, junio 1938.

48 Noticia publicada en Diario La Prensa, 9/2/1938.

49 Corporación Frutícola Argentina, Revista Oficial, Año IV N No 49, marzo 1938. 
puerto de Buenos Aires siguió concentrando hasta el fin de la etapa la producción para exportar, debido, sobre todo, a la política tarifaria de la empresa ferroviaria y al peso de la A.F.D..

Otro problema para la exportación lo constituía la exigua capacidad frigorífica de las compañías navieras, lo que imposibilitó en esos años el total aprovechamiento de la potencialidad ofrecida por los mercados del sur de los EE.UU. -luego de la habilitación del puerto de Nueva Orleans en 1936- y del Brasil. Estos mercados cobraron importancia cuando, por efecto del cierre del mercado europeo a causa de la guerra, la producción argentina se vió en la necesidad de acrecentar su colocación en los países americanos, a la vez que intensificar el consumo interno y el aprovechamiento industrial de la fruta sobrante (secaderos). Solucionado el conflicto y recuperados los mercados europeos, la exportación de manzanas y peras -principalmente las primeras- sufriría un notable incremento cuyo tratamiento excede los límites del presente trabajo.

Con referencia al rol del Estado Nacional en el desenvolvimiento de la fruticultura regional, podemos afirmar que éste se limitó a brindar las facilidades necesarias para la intervención directa del capital británico. La única excepción la constituirian la firma de convenios bilaterales de comercialización y la creación en 1934 de la División de Contralor Oficial de la Producción Frutícola -elevada a la categoría de Dirección en 1936- que dependiente del Mrio. de Agricultura de la Nación abarcaba aspectos no cubiertos por la actividad privada, desde la vigilancia sanitaria de las plantaciones y el correcto empaque de la fruta hasta la inspección portuaria y la autorización de los embarques ${ }^{50}$. Este organismo, surgido a instancias de los agentes vinculados a la exportación, apuntaba a asegurar la calidad del producto en función de las exigencias del mercado externo. La creación del instituto Argentino de Promoción del Intercambio (IAPI) durante el gobierno peronista no incluyó a la fruticultura por considerarla "cultivo especial". Por lo tanto, hasta 1948, el capital privado inglés, a través de la empresa del Ferrocarril del Sud y sus subsidiarias, dominó la evolución de la fruticultura valletana en forma altamente significativa con respecto al capital privado nacional y a la acción desarrollada por el Estado.

50 Corporación Frutícola Argentina, Revista Oficial, Año II, N²3, noviembre 1936. 


\section{Posibilidades de acumulación del pequeño productor frutícola}

Todo hace suponer que el capital británico captó gran parte de los excedentes producidos por la actividad, logrando la mayor capacidad de acumulación dentro del subsistema frutícola regional. Sin embargo, la sostenida expansión de los cultivos, el monopolio productivo de la zona y el predominio de las pequeñas chacras de hasta 10 ha, nos permiten inferir también la rentabilidad de estas explotaciones. A pesar del traspaso, sin duda significativo, de parte del valor generado a otros actores sociales como la A.F.D., los pequeños productores lograron una tasa de ganancia positiva que les posibilitó acceder a las nuevas tecnologías existentes en el mercado y entrar en un ciclo de acumulación con crecimiento, traducible en el grado de prosperidad que los caracterizara a lo largo de la etapa ${ }^{51}$.

Una primera aproximación cuantitativa a las posibilidades de acumulación del actor social que nos ocupa -en tanto pequeño productor propietario de una parcela media de 10 ha- en la etapa de mayor auge de la actividad durante el dominio del capital británico (1930-1948), puede extraerse del ejemplo desarrollado en una tesis doctoral édita del año 1940 donde se calcula, sobre la base del análisis de costo de producción y de acuerdo a los precios máximos cotizados en ese año, las utilidades que quedaron al pequeño productor cuando aún no se habían hecho evidentes los efectos de la contienda internacional sobre la composición de los mercados externos ${ }^{52}$. Por otra parte, esos años marcan también el punto de inflexión donde la pera, en su variedad Williams, fue reemplazada por la manzana Deliciosa que comenzó a rendir mayores beneficios al obtener los mejores precios internacionales. Esto es de fundamental importancia por cuanto el monto final del excedente a distribuir dependía de la posibilidad de colocación en el mercado externo.

Aún cuando el mencionado ejemplo ya permitía reafirmar la hipótesis respecto a las posibilidades de acumulación del pequeño productor frutícola en la etapa estudiada, desarrollamos una simulación analítica con el objeto de determinar, de manera más ajustada, la tasa de ganancia de este sujeto social. A partir de la aplicación del modelo formal de

51 Durante la IV Conferencia Nacional de Fruticultura realizada en el año 1937 en el Alto Valle, se hace notar expresamente que "...5 ha de manzanos en esta región permiten a una familia vivir holgadamente y en sólido bienestar" (cit. en Diario La Nación, 16/3/1937).

52 Cfr. Wetzler, E., 1940: 112 y 113.

53 Bandieri, S. y Blanco, G., 1997. 
la metodología de subsistemas utilizada en esta investigación al ejemplo histórico antes mencionado, se calculó una tasa de ganancia del 27,2\% para una explotación de 7 hectáreas en plena producción en la cosecha anual de los años 1938/39 ${ }^{53}$. Si se tiene en cuenta que la ganancia neta de esa explotación fue de $\$ 8.256$ y que el precio de una hectárea en producción alcanzó en esos años valores máximos de \$3.500, puede deducirse la importante rentabilidad de la misma y las consecuentes posibilidades de acumulación del pequeño productor en la etapa de pleno funcionamiento del modelo impuesto a la actividad por el capital británico, cuando la producción de frutas argentinas no tenía todavía importantes competidores en el Hemisferio Sur ${ }^{54}$.

De todas maneras, aún suponiendo que estos cálculos sobre la base de una empresa tipo fueran mas o menos representativos de los resultados reales obtenidos por los pequeños productores hacia los años '40, es menester indicar el destino de tal capital a los efectos de visualizar la totalidad del proceso de acumulación. En tal sentido, se observa en esos años una importante inversión del excedente en maquinarias (tractores, rastras de disco, equipos de pulverización mecánica, etc.), en la ampliación del proceso productivo y en bienes de consumo duradero, especialmente viviendas confortables y automóviles. En algunos casos, hemos detectado también la compra de otras chacras de dimensiones similares en el área. Tal como se reconoce en las fuentes periodísticas de la época, el pequeño productor frutícola se mostraba entonces en condiciones de tener una alta calidad de vida y cierta capacidad de reproducirse.

Cabe aclarar que limitar este análisis a las primeras etapas de la actividad no implica considerar que el agotamiento de este modelo productivo haya implicado una alteración inmediata de las posibilidades de acumulación del pequeño productor del Alto Valle. Es más, su situación de prosperidad relativa se afianzó y extendió a los años subsiguientes en relación con la constante demanda, la escasa competencia y los buenos precios en los mercados externos, particularmente Brasil ${ }^{55}$. Sin embargo, puede adelantarse que a partir de

54 Recién entre las décadas de 1960 y 1980 aparecerían los mas serios competidores de la fruta argentina en el Hemisferio Sur, particularmente Sudáfrica y Chile (Véase Tapatta, R., 1984: 11).

55 Con relación a la creciente participación de Brasil en el volumen de exportaciones argentinas de peras y manzanas, pueden verse datos de Gabriel y Cía. S.A., en Series CoRPOFRUT, números varios entre 1956 y 1989, Cipolletti, Río Negro. 
la segunda posguerra se habrían producido cambios estructurales en las relaciones de producción vigentes, que afectarían en el largo plazo las posibilidades de obtención de excedentes por parte de los pequeños productores. Efectivamente, sobre fines de la década del '40 se produjo la expansión de varias empresas de comercialización vinculadas a los grandes centros de distribución mayorista del país -Mercado de Abasto de la ciudad de Buenos Aires-. Estas empresas iniciaron un importante proceso de capitalización en la década del '60 incorporando, a través de créditos subsidiados por el Estado, cambios tecnológicos en el procesamiento de la fruta post-cosecha (sistemas complejos de embalaje, acondicionamiento y red de frío). La aparición de fuertes competidores en el Hemisferio Sud, como Sudáfrica y Chile, impuso exigencias respecto a la calidad de las frutas que no pudieron ser afrontadas por gran parte de los pequeños productores, ya afectados por el incremento del costo de producción y la disminución del precio internacional de la fruta ${ }^{56}$. En el afán de lograr costos competitivos, las empresas antes mencionadas agregaron la producción a sus funciones completando la integración vertical de la actividad. De esta manera, redujeron considerablemente los precios pagados a los productores independientes que fueron cediendo progresivamente sus excedentes al capital concentrado ${ }^{57}$. A estas condiciones estructurales se sumaron, sobre fines de la década del '70, cuestiones de política económica interna que provocaron una crisis generalizada de la fruticultura regional. Los pequeños productores independientes vieron así agudizarse su falta de rentabilidad, su descapitalización y el consecuente atraso tecnológico de sus explotaciones, llegando en la actualidad a niveles de estricta subsistencia o a desaparecer de la actividad.

De esta manera, en los últimos años, las grandes empresas comercializadoras, al in-

56 En el período 1968-72 los costos medios de produccción se incrementaron en un $42.5 \%$ con relación al período 1960-67, en tanto los precios de la fruta sólo aumentaron un 21.8\% (Gerardo de Jong, et alt., 1986: 20). Ello se contradecía con la necesidad de mejorar la calidad para hacer frente a la competencia mencionada (véase Gerardo de Jong, Luis Tiscornia y otros, op.cit., 1994, Cap. V).

57 Entre 1960 y 1980 la relación promedio entre el precio de exportación y el pagado al productor era de aproximadamente un $30 \%$, o sea que el productor recibía por su producción un $30 \%$ de lo que recibía el exportador. Para el año 1980 recibió sólo un 18\% (Cfr. Tapatta H.N. (h), 1982, mimeo). Cabe aclarar que, en términos generales, esa estrategia concentradora que caracterizó a las grandes empresas frutícolas, produciendo un distanciamiento cada vez mayor con los productores independientes, fue una característica común a otras economías agrarias en América Latina como producto de la crisis y el proceso de ajuste de los años '80 (Sobre el tema pueden verse, entre otros, López Cordovez, L., 1990; y García, A., 1981. 
tegrar la actividad y pretender obtener altas tasas de ganancia pese a la crisis, disminuyeron los precios pagados al productor desconociendo la importancia y el rol de las pequeñas empresas en la reproducción ampliada del capital y en la posibilidad de seguir obteniendo tales tasas de ganancia. Al afectarse al estrato fragmentado del capital invertido en la fruticultura, transformando a los pequeños productores familiares en minifundistas, no se hizo otra cosa que agudizar el deterioro en el conjunto de la actividad.

Para concluir, la situación de relativa prosperidad de estos productores que señalamos para los años '40 puede confrontarse, a los efectos comparativos, con un ejemplo mas reciente de similares características. Para ello, se han tomado los resultados obtenidos en un trabajo específico sobre las estrategias de adaptación de los productores marginales del subsistema frutícola regional que, usando la misma metodología, ha procurado medir la tasa de ganancia de distintos agentes sociales. En este caso y a los fines de nuestro objetivo, seleccionamos un agente con una explotación de 8 ha de superficie total, con 4,5 ha de manzana Red Delicious y 3 ha de pera Williams, con sistema de conducción tradicional, uso mayoritario de mano de obra familiar y contratación de mano de obra temporaria. Sobre la base de los precios pagados en la cosecha 1991/92 este productor habría obtenido, para un rendimiento anual de $25.000 \mathrm{~kg} / \mathrm{ha}$, una tasa de ganancia negativa del $-0,1 \%$; y para $30.000 \mathrm{~kg} / \mathrm{ha}$ y $35.000 \mathrm{~kg} / \mathrm{ha}$, una positiva del $3,1 \%$ y $6,3 \%$, respectivamente ${ }^{58}$.

Los resultados alcanzados en el ejemplo histórico son importantes por cuanto, más allá de proporcionar un dato simulado de la tasa de ganancia que podía obtener una pequeña explotación en un año determinado -aunque significativo dentro de una etapa-, y permitir su comparación con otros años y períodos, hacen factible la comprobación cuantitativa del significativo rol desempeñado por las explotaciones familiares en las posibilidades de acumulación del conjunto de la actividad y en sus propias condiciones de acumulación, bajo una determinada estrategia productiva. Al mismo tiempo, constituyen un punto de partida para ahondar en las causas de la aguda crisis que desde hace algunos años afecta a la actividad frutícolta del Alto Valle del río Negro, con especial incidencia en las posibilidades de acumulación del pequeño productor propietario.

58 Cfr. caracterización y matriz correspondiente al Agente III de la tipología de productores marginales en Gerardo de Jong, Luis Tiscornia y otros, 1994. 


\section{Bibliografia}

BARCIA TRELLES, Juan (1923), La agricultura de regadío en los valles superior del río Negro e inferiores del Neuquén y el Limay, Ferrocarril del Sud, Sección de Fomento Rural, Folleto N 9, Bs. As., S.A. Establecimiento Gráfico Argentino.

BENEDIT, J.C. (1921), Estudio de las condiciones de explotación intensiva en los valles del río Negro, Neuquén y Limay, Tesis UNBA, Fac. de Agron. y Veterinaria, Bs.As.

BILDER, Ernesto A. y GARRIZ, Patricia I., (1991) "El cultivo del manzano en Argentina. Situación y perspectivas", en Fruticultura Profesional 38, Barcelona, España, pp. 28-35.

BILDER, Ernesto A., (1992) "El Valle del río Negro y Neuquén. Realidad y teoría económica", en Realidad Económica 105/106. Buenos Aires, IADE, enero-marzo, pp. 159-174.

Consejo Federal de Inversiones, Sec. de Planeamiento de la Pcia. de Río Negro (1977), Análisis y evaluación de la actividad económica y configuración espacial de la Provincia de Río Negro, 3 Tomos, Bs.As., C.F.I.

CONTI, Enrique J. (1932), La explotación agricola en el valle del río Negro. Monografía de una chacra de regadio, F.C.Sud, Secc. Fom. Rural, Public. $N^{\circ}$ 18, Bs. As., Establecimiento Gráfico Argentino.

CORAGGIO, José L. (1987), Los complejos territoriales dentro del contexto de los subsistemas de producción y circulación, Textos del Centro de Investigaciones Ciudad, $\mathbf{N}^{\circ} \mathbf{2}$, Quito, Ecuador.

CIAFARDINI, H. y CRISTIA, C. (1973), Análisis de los procesos que limitan o inducen el desarrollo de una región, sobre la base del estudio de caso Neuquén-Valle de Río Negro, $1^{\circ}$ al $5^{\circ}$ Documentos de Trabajo, Universidad Nacional del Sur, Depto. de Economía, mimeo.

DE JONG, Gerardo, et al., (1986), Subsistema frutícola del Alto Valle del río Negro, Universidad Nacional del Comahue-IDRC (Canadá), Neuquén, policopiado.

DE JONG, Gerardo, Tiscornia, Luis y otros (1993), El minifundio en el Alto Valle del río Negro: estrategias de adaptación, Neuquén, Imprenta UNCo., 1993.

DE JONG, Gerardo (1995), “Economías regionales, cambios estructurales en la fruticultura del Alto Valle", en Realidad Económica 136. Buenos Aires, IADE, noviembre-diciembre.

GARCíA, Antonio (1981), "Naturaleza y límites de la modernización capitalista de la agricultura", en García, Antonio, editor, Desarrollo Agrario y la América Latina, FCE, México.

GOTI, Alfredo (1928), "La colonización en el Valle Superior del río Negro", informe presen- 
tado al Banco Hipotecario Nacional, en Revista del Ferrocarril Sud.

LEVIN, Pablo (1974), Diagnóstico de subsistema, Bs. As., C.F.I., inédito.

LÓPEZ CORDOVEZ, Luis (1990)، "Crisis, políticas de ajuste y agricultura", en Núñez, Orlando, Comp., Lo agrario. Teoria y métodos, San José, Costa Rica, EDUCA.

MAC DONALD, J. (1939), La zona de riego del valle del río Negro, F.C. Sud, Secc. Fom. Rural, Publ. N²6, Bs.As., Establecimiento Gráfico Argentino.

MAIDA de MINOLFI, Esther, La colonización de Vicente Blasco Ibañez y el contingente valenciano en el Alto Valle del río Negro. Formación de la Colonia Cervantes, Serie Estudios y Documentos $N^{\circ} 3$, C.I.C., Viedma, Río Negro.

MAIDA de MINOLFI, Esther (1980), "Colonia General Roca, pionera en la colonización del Alto Valle rionegrino", en Academia Nacional de la Historia, Congreso Nac. de Historia sobre la Conquista del Desierto, T. III, Bs.As.

MANZANAL, Mabel (1983), Agro, industria y ciudad en la Patagonia Norte, Bs.As., Ed. CEUR.

MORINELLI de CAVA, Marta B. (1981), "Colonia agrícola Centenario: problemática en torno a su formación (1897-1933)", en Maida de Minolfi, E., Dir., et alt., Neuquén. La ocupación de la tierra pública en el departamento Confluencia después de la Campaña al Desierto (1880-1930), Neuquén, Universidad Nacional del Comahue-Vallegraft Offset S.A.

OCKIER, María C. (1987), Propiedad de la tierra y renta del suelo: la especificidad del Alto Valle del río Negro, CIHES, Fac. de Cs.Económicas, UBA, Documento de Trabajo Nº 1.

OCKIER, María C. (1988), "Inmigrantes y elites en la distribución de la tierra de la Colonia Roca (Río Negro)", en Anuario, Dpto. de Historia, Universidad Nacional de Rosario, N 13.

REGIND, William (1929), "Historia del gran Ferrocarril del Sud desde el año 1862 hasta la fecha", en números varios Revista Ferrocarril del Sud, Bs.As.

ROFMAN, Alejandro, (1984) "Subsistemas espaciales y circuitos de acumulación regional", en Revista Interamericana de Planificación, SIAP, Vol. XVIII, Nº70, México.

Secretaría de Estado de Agric., Ganad. y Pesca, INTA (1986), Diagnóstico Regional, Est. Exp. Reg. Agrop. Alto Valle, Río Negro.

TAPATTA, Heber N. (h) (1982), Precios al productor y precios de exportación de la fruticultura regional: ¿una evidencia de cambios?, Simposio sobre Viabilidad Futura del Modelo de Desarrollo del Alto Valle, General Roca, Río Negro, noviembre، mimeo. 
TAPATTA, Ricardo (1984), Apogeo y crisis de la fruticultura del Comahue, IERAL, Fundación Mediterránea, Cipolletti, Río Negro.

VAPNARSKY, César A. (1983), Pueblos del Norte de la Patagonia (1879-1957), Gral. Roca, Río Negro, Ed. de la Patagonia. 
CUADRO N'1: Tamaño de las unidades de explotación agricola sobre propiedades empadronadas al $31 / 12 / 1927$

\begin{tabular}{|c|c|c|c|c|c|c|c|c|c|c|c|c|}
\hline \multirow{2}{*}{$\begin{array}{l}\text { TAMAÑO } \\
\text { DE LAS } \\
\text { UNIDADES }(\mathrm{Ha})\end{array}$} & \multicolumn{2}{|c|}{ ZONA I } & \multicolumn{2}{|c|}{ ZONA II } & \multicolumn{2}{|c|}{ ZONA III } & \multicolumn{2}{|c|}{$\begin{array}{l}\text { ZONA } \\
\text { IV a VII }\end{array}$} & \multicolumn{2}{|c|}{$\begin{array}{l}\text { TOTAL RIO } \\
\text { NEGRO SUPER. }\end{array}$} & \multicolumn{2}{|c|}{$\begin{array}{l}\text { ZONA CHACRAS } \\
\text { NEUQUEN }\end{array}$} \\
\hline & $\mathbf{N}^{\circ}$ & $\%$ & $\mathbf{N}^{\circ}$ & $\%$ & $\mathbf{N}^{\circ}$ & $\%$ & $\mathbf{N}^{\circ}$ & $\%$ & $\mathbf{N}^{\circ}$ & $\%$ & $\mathbf{N}^{\circ}$ & $\%$ \\
\hline MENOS DE 1 & 3 & 2 & 1 & 1 & 6 & 1 & 75 & 19 & 85 & 7 & 84 & 27 \\
\hline $\begin{array}{lll}1 & \text { A } & 10\end{array}$ & 62 & 37 & 38 & 38 & 230 & 42 & 62 & 15 & 392 & 32 & 149 & 48 \\
\hline 10 A 20 & 69 & 42 & 20 & 20 & 82 & 15 & 30 & 7 & 201 & 16 & 49 & 16 \\
\hline 20 A 30 & 18 & 11 & 13 & 13 & 45 & 8 & 28 & 7 & 104 & 9 & 17 & 6 \\
\hline $\begin{array}{lll}30 & \text { A } & 40\end{array}$ & 4 & 2 & 5 & 5 & 32 & 6 & 20 & 5 & 61 & 5 & 1 & 0 \\
\hline $\begin{array}{lll}40 & \mathrm{~A} & 50\end{array}$ & 2 & 1 & 2 & 2 & 46 & 9 & 34 & 8 & 84 & 7 & 3 & 1 \\
\hline $50 \quad$ A 100 & - & - & 8 & 8 & 101 & 18 & 144 & 35 & 253 & 21 & - & - \\
\hline MAS DE 100 & 8 & 5 & 13 & 13 & 5 & 1 & 16 & 4 & 42 & 3 & 5 & 2 \\
\hline $\begin{array}{l}\text { TOTAL DE } \\
\text { LOTES }\end{array}$ & 166 & 100 & 100 & 100 & 547 & 100 & 409 & 100 & 1.222 & 100 & 300 & 100 \\
\hline
\end{tabular}

Nota: Los datos referidos a la Zona Chacras Neuquén se consignan por separado por cuanto el organismo especifico no incluye a la misma dentro de los totales del Río Negro Superior.

Fuente: Elaboración propia sobre datos M.O.P., D.G.I., Intendencia de Riego del Rio Negro Superior, Gral. Roca (R.N.), Memoria Anual 1928.

CUADRO $N^{\circ}$ 2: Tamaño de las unidades de explotación agrícola sobre propiedades empadronadas Zona VII a XVIII, al 31/12/1928.

\begin{tabular}{|ccc|c|c|}
\hline \multirow{2}{*}{$\begin{array}{l}\text { TAMAÑO } \\
\text { DE LAS } \\
\text { UNIDADES (Ha) }\end{array}$} & \multicolumn{2}{|c|}{ ZONA } \\
\cline { 2 - 5 } & VIII a XVIII & $\mathbf{N}^{\circ}$ & $\%$ \\
\hline 1 & A & 10 & 46 & 21 \\
\hline 10 & A & 20 & 33 & 15 \\
\hline 20 & A & 50 & 16 & 7 \\
\hline 50 & A & 100 & 110 & 49 \\
\hline MAS & DE & 100 & 17 & 8 \\
\hline $\begin{array}{c}\text { TOTAL DE } \\
\text { LOTES }\end{array}$ & 222 & 100 \\
\hline
\end{tabular}

Nota: Los datos referidos a esta zona no se incluyen en el Cuadro $\mathrm{N}^{\circ} 1$ por cuanto recién se incorpora al sistema integral de riego en 1928.

Fuente: Memoria anual 1929. 
CUADRO N 3: Tamaño de las unidades de explotación agricola sobre propiedades empadronadas al 31/12/1947

\begin{tabular}{|c|c|c|c|c|c|c|c|c|c|c|c|c|}
\hline \multirow{2}{*}{$\begin{array}{l}\text { TAMAÑO } \\
\text { DE LAS } \\
\text { UNIDADES }(\mathrm{Ha})\end{array}$} & \multicolumn{2}{|c|}{ ZONA I } & \multicolumn{2}{|c|}{ ZONA II } & \multicolumn{2}{|c|}{ ZONA III } & \multicolumn{2}{|c|}{$\begin{array}{l}\text { ZONA } \\
\text { IV a VII }\end{array}$} & \multicolumn{2}{|c|}{$\begin{array}{l}\text { ZONA } \\
\text { VIII a XVIII }\end{array}$} & \multicolumn{2}{|c|}{$\begin{array}{l}\text { TOTAL RIO } \\
\text { NEGRO SUPER. }\end{array}$} \\
\hline & $\mathbf{N}^{\circ}$ & $\%$ & $\mathbf{N}^{\circ}$ & $\%$ & $\mathbf{N}^{\circ}$ & $\%$ & $\mathbf{N}^{\circ}$ & $\%$ & $\mathbf{N}^{\circ}$ & $\%$ & $\mathbf{N}^{\circ}$ & $\%$ \\
\hline MENOS DE 1 & 51 & 11 & 133 & 16 & 83 & 6 & 10 & 2 & 8 & 1 & 285 & 8 \\
\hline $\begin{array}{lll}1 & \mathrm{~A} & 5 \\
\end{array}$ & 195 & 40 & 231 & 29 & 405 & 30 & 67 & 16 & 63 & 10 & 960 & 26 \\
\hline $\begin{array}{lll}5 & \text { A } & 20\end{array}$ & 121 & 25 & 216 & 26 & 277 & 21 & 60 & 14 & 154 & 25 & 828 & 22 \\
\hline $\begin{array}{lll}10 & A & 20 \\
\end{array}$ & 90 & 19 & 187 & 22 & 303 & 23 & 75 & 18 & 264 & 43 & 919 & 25 \\
\hline 20 A 30 & 18 & 4 & 43 & 5 & 108 & 8 & 87 & 21 & 43 & 7 & 299 & 8 \\
\hline 30 A 50 & 4 & 1 & 18 & 2 & 82 & 6 & 72 & 17 & 33 & 5 & 209 & 6 \\
\hline 50 A 100 & 1 & 0 & 6 & 1 & 71 & 5 & 52 & 12 & 47 & 8 & 177 & 5 \\
\hline MAS DE 100 & 3 & 0 & 5 & 0 & 5 & 1 & 1 & 0 & 8 & 1 & 22 & 0 \\
\hline $\begin{array}{l}\text { TOTAL DE } \\
\text { LOTES }\end{array}$ & 482 & 100 & 839 & 100 & 1.334 & 100 & 424 & 100 & 620 & 100 & 3.699 & 100 \\
\hline
\end{tabular}

\begin{tabular}{|c|c|c|}
\hline \multirow{2}{*}{$\begin{array}{l}\text { TAMAÑO } \\
\text { DE LAS } \\
\text { UNIDADES }(\mathrm{Ha})\end{array}$} & \multicolumn{2}{|c|}{ ZONA CHACRAS NEUQUEN } \\
\hline & $\mathbf{N}^{\circ}$ & $\%$ \\
\hline MENOS DE 1 & 112 & 19 \\
\hline $\begin{array}{lll}1 & A & 5\end{array}$ & 167 & 29 \\
\hline $5 \quad$ A 10 & 133 & 23 \\
\hline 10 A 20 & 127 & 22 \\
\hline 20 A 30 & 28 & 5 \\
\hline 30 A 50 & 6 & 2 \\
\hline 50 A 100 & 5 & 1 \\
\hline MAS DE 100 & 5 & 1 \\
\hline $\begin{array}{l}\text { TOTAL DE } \\
\text { LOTES }\end{array}$ & 583 & 100 \\
\hline
\end{tabular}

Nota: Para el organismo empadronador "Río Negro Superior" incluye el área comprendida entre Contralmirante Cordero y Chichinales (Zonas I a XVIII). Ello obliga a consignar por separado los datos correspondientes a "Chacras Neuquén".

Fuente: Elaboración propia sobre datos de la Secretaría de Industria y Comercio, Dcción. Gral. de Agua y Energía Eléctrica, Intendencia de Riego del Río Negro Superior, Gral. Roca (R.N.), Memoria Anual 1947. 
CUADRO N' 4: Tráfico despachado por las Estaciones del Ferrocarril del sud en el área del Alto Valle. Años agrícolas $1920 / 21$ a $1946 / 47$ (En toneladas y porcentajes)

\begin{tabular}{|c|c|c|c|c|c|}
\hline AÑOS & $\begin{array}{l}\text { TOTAL CARGA } \\
\text { DESPACHADA }\end{array}$ & $\begin{array}{l}\text { TOTAL PASTO EN } \\
\text { FARDOS CHICOS }\end{array}$ & $\begin{array}{c}\% \text { SOBRE EL } \\
\text { TOTAL CARGAS }\end{array}$ & $\begin{array}{l}\text { TOTAL FRUTAS } \\
\text { Y LEGUMBRES }\end{array}$ & $\begin{array}{c}\% \text { SOBRE EL } \\
\text { TOTAL CARGAS }\end{array}$ \\
\hline $1920 / 21$ & 68.657 & 44.350 & 65 & 1.066 & 1 \\
\hline $1921 / 22$ & 74.907 & 52.363 & 70 & 1.749 & 2 \\
\hline $1922 / 23$ & 92.239 & 68.056 & 74 & 1.096 & 1 \\
\hline $1923 / 24$ & 78.771 & 54.387 & 69 & 1.436 & 2 \\
\hline $1924 / 25$ & 100.957 & 67.644 & 67 & $\mathrm{n}$ & - \\
\hline $1925 / 26$ & 95.141 & 61.227 & 64 & 2.727 & 3 \\
\hline $1926 / 27$ & 94.421 & 55.108 & 58 & 3.821 & 4 \\
\hline $1927 / 28$ & 138.171 & 96.125 & 70 & 3.082 & 2 \\
\hline $1928 / 29$ & 150.229 & 104.863 & 70 & 4.061 & 3 \\
\hline $1929 / 30$ & 129.067 & 71.495 & 55 & 6.169 & 5 \\
\hline $1930 / 31$ & 101.572 & 41.999 & 41 & 6.315 & 6 \\
\hline $1931 / 32$ & 99.209 & 35.138 & 35 & 11.455 & 11 \\
\hline $1932 / 33$ & 105.212 & 30.818 & 29 & 14.646 & 14 \\
\hline $1933 / 34$ & 141.651 & 43.299 & 30 & 16.109 & 11 \\
\hline $1934 / 35$ & 148.904 & 34.897 & 23 & 29.516 & 20 \\
\hline $1935 / 36$ & 160.875 & 50.736 & 31 & 40.766 & 25 \\
\hline $1936 / 37$ & 197.520 & 55.933 & 28 & 65.693 & 33 \\
\hline $1937 / 38$ & 219.262 & 69.000 & 31 & 70.119 & 32 \\
\hline $1938 / 39$ & 203.786 & 39.923 & 19 & 86.789 & 42 \\
\hline $1939 / 40$ & 176.653 & 22.253 & 13 & 65.411 & 37 \\
\hline $1940 / 41$ & 213.471 & 12.278 & 6 & 84.920 & 40 \\
\hline $1941 / 42$ & 200.209 & 5.635 & 3 & 50.815 & 25 \\
\hline $1942 / 43$ & 232.717 & 20.950 & 9 & 97.473 & 42 \\
\hline $1943 / 44$ & 178.791 & 19.677 & 11 & 106.135 & 59 \\
\hline $1944 / 45$ & 205.489 & 18.494 & 9 & 125.635 & 61 \\
\hline $1945 / 46$ & 275.896 & 18.652 & 7 & 155.022 & 58 \\
\hline $1946 / 47$ & 236.737 & 19.330 & 9 & 142.090 & 63 \\
\hline
\end{tabular}

Fuente: Elaboración propia sobre datos de la Secretaría de Industria y Comercio, Dirección General de Agua y Energía Eléctrica, Intendencia de Riego del Río Negro Superior, Memorias anuales años agrícolas 1920/21 a $1946 / 47$ 
CUADRO N' 5: Porcentajes de superficies cultivadas en hectáreas según cultivos más representativos en Río Negro Superior y Chacras Neuquén, entre los años 1927 y 1946.

\begin{tabular}{|c|c|c|c|c|}
\hline \multicolumn{5}{|c|}{ RIO NECRO SUPERIOR (\%) } \\
\hline AÑOS & ALFALFA & VIÑA & FRUTALES & $\begin{array}{c}\text { CEREALES Y } \\
\text { HORTALIZAS }\end{array}$ \\
\hline 1927 & 76 & 12 & 6 & 6 \\
\hline 1928 & 71 & 15 & 8 & 6 \\
\hline 1929 & 64 & 15 & 10 & 11 \\
\hline 1930 & 58 & 17 & 12 & 12 \\
\hline 1931 & 53 & 19 & 14 & 14 \\
\hline 1932 & 52 & 20 & 17 & 11 \\
\hline 1933 & 48 & 20 & 18 & 14 \\
\hline 1934 & -- & -- & - & -- \\
\hline 1935 & 51 & 19 & 20 & 10 \\
\hline 1936 & -- & - & - & - \\
\hline 1937 & -- & -- & - & - \\
\hline 1938 & 47 & 16 & 21 & 16 \\
\hline 1939 & 53 & 16 & 22 & 9 \\
\hline 1940 & -- & - & - & -- \\
\hline 1941 & -- & - & -- & - \\
\hline 1942 & -- & - & - & - \\
\hline 1943 & -- & -- & - & - \\
\hline 1944 & -- & -- & - & -- \\
\hline 1945 & 46 & 13 & 19 & 12 \\
\hline 1946 & 43 & 13 & 21 & 13 \\
\hline
\end{tabular}

\begin{tabular}{|c|c|c|c|c|}
\hline \multicolumn{2}{|c|}{ ZOA CHACRAS NEUQUEN (\%) } \\
\hline AÑOS & ALFALFA & VIÑA & FRUTALES & $\begin{array}{c}\text { CEREALES Y } \\
\text { HORTALIZAS }\end{array}$ \\
\hline 1927 & 69 & 13 & 3 & 15 \\
\hline 1928 & 64 & 14 & 10 & 12 \\
\hline 1929 & 59 & 9 & 8 & 24 \\
\hline 1930 & 41 & 17 & 12 & 30 \\
\hline 1931 & 34 & 15 & 17 & 34 \\
\hline 1932 & 42 & 17 & 14 & 27 \\
\hline 1933 & 44 & 17 & 15 & 24 \\
\hline 1934 & 45 & 19 & 16 & 20 \\
\hline 1935 & 48 & 16 & 20 & 16 \\
\hline 1936 & 54 & 13 & 20 & 13 \\
\hline 1937 & 57 & 11 & 19 & 13 \\
\hline 1938 & 62 & 9 & 19 & 10 \\
\hline 1939 & 64 & 7 & 7 & 12 \\
\hline 1940 & 56 & 9 & 19 & 16 \\
\hline 1941 & 49 & 9 & 16 & 26 \\
\hline 1942 & 50 & 8 & 20 & 22 \\
\hline 1943 & 50 & 9 & 22 & 19 \\
\hline 1944 & 57 & 9 & 20 & 14 \\
\hline 1945 & 51 & 11 & 26 & 12 \\
\hline 1946 & 50 & 10 & 26 & 14 \\
\hline
\end{tabular}

Nota: Al igual que en los cuadros anteriores y por las mismas razones señaladas, se consignan por separado los datos referidos a la Zona de Chacras Neuquén. Para los años en blanco no se obtuvo información.

Fuente: Elaboración propia sobre datos de explotación extraídos de las Memorias Anuales de la Intendencia de Riego del Río Negro Superior, entre los años 1927 y 1946 


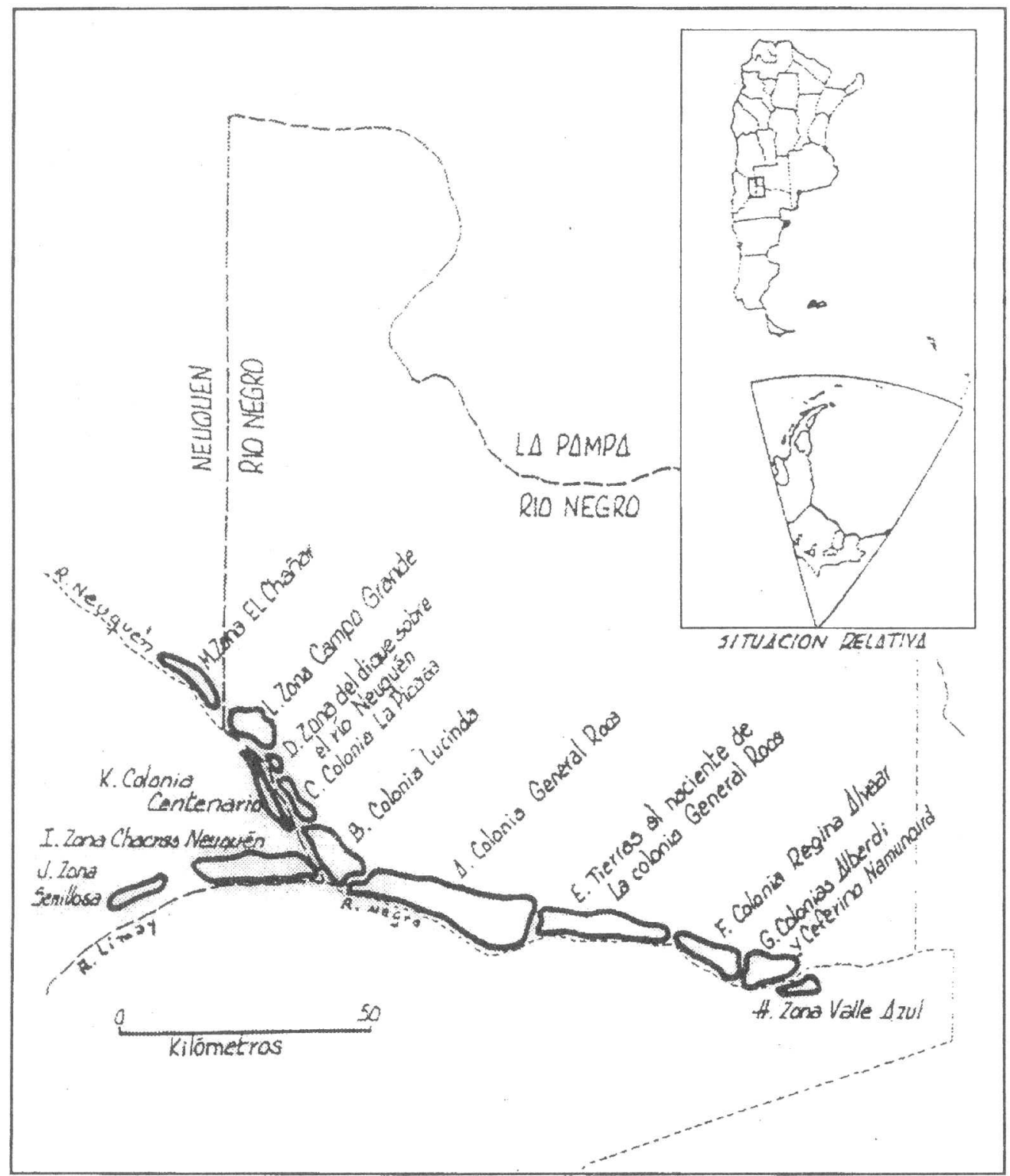

